\title{
Tracing Future Spring and Summer Drying in Southern Africa to Tropical Lows and the Congo Air Boundary ${ }^{\mathcal{O}}$
}

\author{
EMMA HOWARD AND RICHARD WASHINGTON \\ School of Geography and the Environment, University of Oxford, Oxford, United Kingdom
}

(Manuscript received 10 October 2019, in final form 21 April 2020)

\begin{abstract}
In southern Africa, models from phase 5 of the Coupled Model Intercomparison Project (CMIP5) predict robust future drying associated with a delayed rainy-season onset in the austral spring and a range of wetting and drying patterns in the austral summer. This paper relates these rainfall changes to dynamical shifts in two classes of weather systems: the Congo Air Boundary (CAB) and tropical lows. Objective algorithms are used to track these features in CMIP5 model output. It is then established that the climatological locations and frequencies of these systems are reasonably well represented in the CMIP5 models. RCP8.5 end-of-twentyfirst-century projections are compared with historical end-of-twentieth-century simulations. Future projections in tropical-low locations and frequencies diverge, but indicate an overall average decrease of $15 \%$ and in some cases a northward shift. The projected spatial change in the tropical-low frequency distribution is weakly positively correlated to the projected spatial change in the austral summer rainfall distribution. Meanwhile, future projections indicate a $13 \%$ increase in CAB frequency from October to December. This is associated with the gradual climatological CAB breakdown occurring half a month later on average in end-of-twenty-first-century RCP8.5 projections. A delay in the gradual seasonal decline of the $\mathrm{CAB}$ prevents rainfall to the south of the CAB's mean position, most of which is shown to occur on CAB breakdown days, hence creating the austral spring drying signal and delayed wet-season onset. Intermodel variability in the magnitude of $C A B$ frequency increase is able to explain intermodel variability in the projected drying.
\end{abstract}

\section{Introduction}

CMIP5-based rainfall projections exhibit a rainfall decline over southern Africa which is strongest in the October-December (OND) season (James and Washington 2013). This rainfall decline has been linked with a delay in the onset date of the rainy season (Dunning et al. 2018) and in many models comes with an increase in rainfall in central Africa in the same season (Aloysius et al. 2016; Creese et al. 2019). Southern Africa is highly vulnerable to climaterelated socioeconomic risk, as the regional water resource supports the local food-energy-water nexus (Conway et al. 2015). In particular, rainy-season onset and cessation dates are particularly important for farmers and other stakeholders (Hachigonta et al. 2008). Some studies have found

\footnotetext{
Supplemental information related to this paper is available at the Journals Online website: https://doi.org/10.1175/JCLI-D-190755.s1.

Corresponding author: Emma Howard, e.r.howard@reading.ac.uk
}

consistent delays of southern African wet-season onset in satellite and gauge-based observational datasets covering the late twentieth and early twenty-first centuries (e.g., Jiang et al. 2019; Kniveton et al. 2009). Delayed rainfall onset would shorten the growing season, as no corresponding delay in cessation has been projected (Dunning et al. 2018). This will reduce the agricultural viability of the region and have follow-on effects on regional food security and economic growth (Lobell et al. 2008; Schlenker and Lobell 2010).

At first glance, the southern African drying trend appears to follow that of the broader subtropical drying trend. However, closer analysis reveals that in southern Africa, the drying occurs primarily north of the subtropical rainfall minimum (Scheff and Frierson 2012a,b). Furthermore, while the subtropical drying signal is largely characterized by an increase in the magnitude of the difference between precipitation and evaporation $(P-E)$, in southern Africa evaporation decreases in line with precipitation, so that $P-E$ does not change considerably. Lazenby et al. (2018) demonstrated 
that the southern African drying trend is primarily a consequence of circulation changes, rather than thermodynamic mechanisms such as dry-get-drier (Held and Soden 2006) or upped-ante (Chou et al. 2009). Thus, the southern African drying trend is dynamically unique and requires a bespoke approach.

Some work has been done on understanding the dynamics of projected rainfall change in southern Africa. Lazenby et al. (2018) found that this change could be viewed as a northward shift of the African rainband, while Dunning et al. (2018) linked the delayed onset of OND rains in southern Africa to relative changes in the strengths of the Saharan and Angolan heat lows. Munday and Washington (2019) found a complementary result: models with a deeper future climatological Angola heat low showed a higher intensity of drying. Similarly, Cook and Vizy (2013) observed a strengthening of the Angola low in regional climate model simulations. However, little work has been done to directly link rainfall change to changes in precipitating weather systems.

Meanwhile, less work has looked at rainfall change in December-February (DJF), the peak of the wet season (van Heerden and Taljaard 1998). Model projections disagree in this season, although Lazenby et al. (2018) suggest that intermodel differences in SST trends in adjacent oceans may explain the diverse range of model projections. Once again, the characteristics of the future change patterns of atmospheric features on synoptic time scales have not been studied.

Since atmospheric circulation on climatological time scales is the aggregation of synoptic weather systems, future circulation change hinges on the response of synoptic weather systems to a warmer atmosphere. However, the synoptic weather systems that occur in the southern African tropical margins are understudied. The representation of such synoptic weather systems in CMIP5 models and their future change has not been studied. This knowledge gap ensures that the synoptic context of the future change signal in this region, and whether or not a specific class of weather system may deliver the projected change, is unknown.

This paper focuses on two local classes of weather systems that occur in the latitudinal band of the advancing spring rains and have previously been associated with rainfall variability. The first is the Congo Air Boundary ( $\mathrm{CAB})$, a combined surface dryline and convergence line that marks the boundary between tropical and subtropical weather zones in the austral spring (Howard and Washington 2019). The second class of weather systems considered are tropical lows, cyclonic rotating vortices that form in the austral summer and tend to cluster near $20^{\circ} \mathrm{S}$, creating the climatological Angola tropical low (Howard and Washington 2018). By examining the representation of the $\mathrm{CAB}$ and tropical lows in historical coupled climate models, this work follows a process-based model evaluation framework. After establishing whether these systems are well modeled, we then proceed to studying process-based projections. This involves investigating how the $\mathrm{CAB}$ and tropical lows are projected to change according to RCP8.5 endof-twenty-first-century simulations.

Both of these weather systems were identified by Taljaard (1986) as 2 of the 10 most important factors that influence the weather over southern Africa. Crucially, they both operate on length scales that are large enough to be resolved in CMIP5 models. The focus of this work is on the austral spring and summer seasons, since the former is the season with the strongest rainfall change, and the latter is the main rainy season. Our analysis will show that changes in tropical lows and the $\mathrm{CAB}$ are vitally important for future projections of southern African precipitation, as they directly influence the delivery of model precipitation. However, this result does not preclude changes in other factors, including the distribution of sea surface temperatures, the subtropical jet and high pressure belt, and upper-level waves, from also playing a role. Indeed, it is possible that the circulation changes of tropical lows and the $\mathrm{CAB}$ are linked to changes in these other systems.

The CAB has historically been defined as the confluence zone between the Congo air mass, a moist and convectively active region of air that sits over the Congo rain forest, and the drier trade easterlies that cross southern Africa and originate from the Indian Ocean (Taljaard 1972). The CAB was originally discussed in the context of identifying the elusive ITCZ over southern and eastern Africa (Taljaard 1953). It was argued that the CAB could not be the ITCZ itself, as both airmasses involved originate from the Southern Hemisphere (the Congo air mass being associated with the recurvature of the South Atlantic trade winds, known locally as the low-level westerlies; e.g., Leroux 2001). However, the importance of the $\mathrm{CAB}$ for southern African rainfall was undisputed (Torrance 1979).

Despite its importance to the local climate, no systematic study of the representation of the $\mathrm{CAB}$ in reanalysis or model products had been performed before Howard and Washington (2019). They optimized an edge-detecting algorithm and a ridge-detecting algorithm to pick out sharp gradients in specific humidity and ridges in wind convergence that were associated with the southern portion of the CAB. They distinguished between the "dryline" $\mathrm{CAB}$ and a "convergence line" CAB based on the choice of algorithm and determined that although the two were closely comparable, the dryline algorithm was slightly more reliable. Howard and Washington (2019) also identified 
the Kalahari Discontinuity (KD), a similar near-surface dryline/convergence line system located farther south and oriented parallel to the west coast of southern Africa, that forms after the $\mathrm{CAB}$ breaks down in October and November. They confirmed that the CAB latitude and detection frequency were closely linked to the interannual variability of spring rainfall over southern Africa. This suggests that the future change of the $\mathrm{CAB}$ has potential explanatory power for the OND drying.

Southern African tropical lows are synoptic-scale cyclonic vortices with depths up to $500 \mathrm{hPa}$ that track predominantly westward across the southern African continent (Howard and Washington 2018). They are precipitating systems, and cluster in eastern Angola and western Zambia, where they tend to become semistationary (Howard et al. 2019). In southern Africa, tropical lows have been most commonly studied in the form of their climatological mean, the Angola tropical low (e.g., Cook et al. 2004; Crétat et al. 2018; Pascale et al. 2019). Since the Angola tropical low has been closely linked to interannual rainfall variability (Reason and Jagadheesha 2005; Cook et al. 2004), considerable attention has been paid to how it is simulated in various models. Lazenby et al. (2016) and Munday and Washington (2017) both found that the Angola low is excessively strong in historical climate models, and linked this to the wet bias over southern Africa. However, the representation of the Angola tropical low on synoptic time scales in CMIP5 models, and its future change, has not yet been assessed.

The goal of this paper is to express projected rainfall changes from the viewpoint of projected changes in synoptic weather systems. This involves first linking the spring drying signal to projected changes in characteristics of the $\mathrm{CAB}$, and also linking the summer intermodel spread of rainfall projections with the intermodel spread of changes to the spatial distribution and frequencies of tropical lows and the CAB. To achieve this aim, the paper proceeds as follows. In section 2 , the models, datasets, and feature identification algorithms are described. In section 3 , we consider the historical representation of the $\mathrm{CAB}$, the CAB's projected future change, and the rainfall implications of that projected change. In section 4 , we perform a similar analysis on tropical lows. In the final section, we summarize the importance of this work for understanding rainfall change in southern Africa.

\section{Methods}

\section{a. Models and reanalysis datasets}

A selection of 25 CMIP5 models has been used in this study, based on the availability of the appropriate model output variables. To study the $\mathrm{CAB}$, we require daily surface-level specific humidity and temperature data, which 18 of these models had available. To study tropical lows, we required 6-hourly wind data on pressure levels, which was available in a different subset of 18 models. The model names, creators, and grid spacings are shown in Table 1, together with a list of which models were used to study the $\mathrm{CAB}$ and tropical lows. For each model, 30 years of end-of-twentieth-century coupled climate model output were examined, and compared to 30 years of end-of-twenty-first-century model output generated under the RCP8.5 coupled model scenario. More precisely, the CAB was studied between August 1970 and December 1999 of each century, and tropical lows were studied between November 1969 and March 1999. The simulated historical climatology of each feature was compared to the reanalysis climatologies from three reanalysis products: ERA5, ERA-Interim, and MERRA-2. Reanalysis climatologies were taken from the 30-yr period of 1980-2010.

The $\mathrm{CAB}$ has been identified between August and December, and its correlation with rainfall change has been studied between October and December. The former season has been chosen because this is the season in which the $\mathrm{CAB}$ is present in southern Africa, and the season in which validation against the results of Howard and Washington (2019) was possible. The latter season was chosen because it is the season of maximum rainfall decline in southern Africa (Munday and Washington 2019). Tropical lows were identified between November and March, and their influence on future rainfall change was studied between December and February. Again, the former is the season in which tropical lows are present in southern Africa (Howard et al. 2019). The latter is the main wet season in southern Africa, and is also the season in which the contribution of tropical lows toward southern African rainfall is most significant (Howard et al. 2019). The OND precipitation decline across the two 30 -yr time periods is greater than the 30 -yr decadal standard deviation as calculated from the corresponding preindustrial control experiments in over $50 \%$ of the models considered, as indicated by Fig. S1 in the online supplemental material. This was not the case in DJF.

\section{b. Congo Air Boundary}

This paper adapts the methodology of Howard and Washington (2019) to identify the CAB in CMIP5 models. Because they studied the $\mathrm{CAB}$ in a highresolution $\left(\sim 0.25^{\circ}\right)$ reanalysis dataset, and the models employed here have resolutions ranging from $\sim 1^{\circ}$ to $3^{\circ}$, this methodology needs a few modifications in order to transfer over to lower resolutions. Properties of the 
TABLE 1. List of CMIP5 models and reanalysis products considered in this study, together with horizontal grid spacings, and an indication of whether the model was used to study the CAB, tropical lows (TL), or both.

\begin{tabular}{|c|c|c|c|c|}
\hline & Institute & Horizontal spacing & $\mathrm{CAB}$ & TL \\
\hline \multicolumn{5}{|c|}{ CMIP models } \\
\hline BCC-CSM1.1-m & Beijing Climate Center, China Meteorological Administration & $1.125^{\circ} \times 1.125^{\circ}$ & $\checkmark$ & $\checkmark$ \\
\hline BNU-ESM & $\begin{array}{l}\text { College of Global Change and Earth System Science, Beijing } \\
\text { Normal University }\end{array}$ & $2.8^{\circ} \times 2.8^{\circ}$ & $\checkmark$ & $\checkmark$ \\
\hline CanESM2 & Canadian Centre for Climate Modelling and Analysis & $2.8^{\circ} \times 2.8^{\circ}$ & $\checkmark$ & $\checkmark$ \\
\hline CNRM-CM5 & Centre National de Recherches Meteorologiques & $1.4^{\circ} \times 1.4^{\circ}$ & $\checkmark$ & $\checkmark$ \\
\hline ACCESS1.0 & $\begin{array}{l}\text { Commonwealth Scientific and Industrial Research } \\
\text { Organization and Bureau of Meteorology, Australia }\end{array}$ & $1.25^{\circ} \times 1.825^{\circ}$ & $\checkmark$ & $\checkmark$ \\
\hline ACCESS1.3 & $\begin{array}{l}\text { Commonwealth Scientific and Industrial Research } \\
\text { Organization and Bureau of Meteorology, Australia }\end{array}$ & $1.25^{\circ} \times 1.825^{\circ}$ & $\checkmark$ & $\checkmark$ \\
\hline CSIRO-Mk3.6.0 & $\begin{array}{l}\text { Commonwealth Scientific and Industrial Research } \\
\text { Organization in collaboration with Queensland Climate } \\
\text { Change Centre of Excellence }\end{array}$ & $1.825^{\circ} \times 1.825^{\circ}$ & $\checkmark$ & \\
\hline INM_CM4 & Institute for Numerical Mathematics, Moscow, Russia & $1.5^{\circ} \times 2.0^{\circ}$ & $\checkmark$ & $\checkmark$ \\
\hline IPSL-CM5A-LR & L'Institut Pierre-Simon Laplace & $1.9^{\circ} \times 3.75^{\circ}$ & $\checkmark$ & $\checkmark$ \\
\hline IPSL-CM5A-MR & L'Institut Pierre-Simon Laplace & $1.25^{\circ} \times 2.5^{\circ}$ & $\checkmark$ & $\checkmark$ \\
\hline IPSL-CM5B-LR & L'Institut Pierre-Simon Laplace & $1.9^{\circ} \times 3.75^{\circ}$ & $\checkmark$ & $\checkmark$ \\
\hline HadGEM2-CC & Met Office Hadley Centre & $1.25^{\circ} \times 1.9^{\circ}$ & $\checkmark$ & $\checkmark$ \\
\hline HadGEM2-ES & Met Office Hadley Centre & $1.25^{\circ} \times 1.9^{\circ}$ & $\checkmark$ & $\checkmark$ \\
\hline MPI-ESM-LR & Max Planck Institute for Meteorology M24 & $1.8^{\circ} \times 1.8^{\circ}$ & & $\checkmark$ \\
\hline MPI-ESM-MR & Max Planck Institute for Meteorology M24 & $1.8^{\circ} \times 1.8^{\circ}$ & & $\checkmark$ \\
\hline NorESM1-M & Norwegian Climate Centre & $1.875^{\circ} \times 2.5^{\circ}$ & $\checkmark$ & $\checkmark$ \\
\hline GFDL CM3 & NOAA/Geophysical Fluid Dynamics Laboratory & $2.0^{\circ} \times 2.5^{\circ}$ & $\checkmark$ & $\checkmark$ \\
\hline GFDL-ESM2G & NOAA/Geophysical Fluid Dynamics Laboratory & $2.0^{\circ} \times 2.5^{\circ}$ & $\checkmark$ & $\checkmark$ \\
\hline GFDL-ESM2M & NOAA/Geophysical Fluid Dynamics Laboratory & $2.0^{\circ} \times 2.5^{\circ}$ & $\checkmark$ & \\
\hline CESM1-CAM5 & Community Earth System Model contributor & $0.94^{\circ} \times 1.25^{\circ}$ & $\checkmark$ & \\
\hline \multicolumn{5}{|c|}{ Reanalyses } \\
\hline ERA5 & European Centre for Medium-Range Forecasting & $0.25^{\circ} \times 0.25^{\circ}$ & $\checkmark$ & $\checkmark$ \\
\hline ERA-Interim & European Centre for Medium-Range Forecasting & $0.75^{\circ} \times 0.75^{\circ}$ & $\checkmark$ & $\checkmark$ \\
\hline MERRA-2 & NASA & $0.5^{\circ} \times 0.75^{\circ}$ & $\checkmark$ & $\checkmark$ \\
\hline
\end{tabular}

$\mathrm{CAB}$ are dependent on the resolution of the input data, and so all models and reanalyses are regridded to a $2^{\circ} \times 2^{\circ}$ grid.

While Howard and Washington (2019) used both wind convergence and humidity to detect the $\mathrm{CAB}$, the present study only uses humidity, and focuses solely on what Howard and Washington (2019) refer to as the "dryline CAB." This choice was made because Howard and Washington (2019) found that the dryline CAB was more reliable and easily detected than the convergence line CAB. Near-surface relative humidity gradients, rather than specific humidity gradients, have been used to calculate the CAB location. This choice has been made to allow for easier comparison between historical and RCP8.5 experiments, given that near-surface specific humidity generally increases by a factor of about 2 across the tropics by the end of the twenty-first century in the RCP8.5 scenario.

The algorithm used to detect the CAB is as follows. Figure 1 shows the algorithm applied to a sample day (9September 1999) from a sample model (ACCESS1.3).
1) The 2-m relative humidity is calculated from 2-m daily mean air temperature (tas), 2-m daily mean specific humidity (huss), and surface pressure (sp), where these fields are available. Where they are not available, the $1000-\mathrm{hPa}$ pressure-level relative humidity (hur) is used instead.

2) Relative humidity is interpolated to a $2^{\circ} \times 2^{\circ}$ grid using a nearest neighbor interpolation scheme. This scheme is chosen in order to avoid differentially smoothing humidity gradients in the higher-resolution datasets during the regridding process. The left panel of Fig. 1 shows the regridded field.

3) In keeping with the Canny (Canny 1986) algorithm, a Gaussian filter with a $2^{\circ}$ radius is used to smooth the relative humidity field. The magnitude $M$ and direction $\theta$ of the gradient were then calculated using finite differences.

4) Canny edges were calculated as per Howard and Washington (2019), thresholding the magnitude of the humidity gradient such that it must undergo an absolute change of $\Delta \mathrm{RH}=40 \%$ between grid cells 

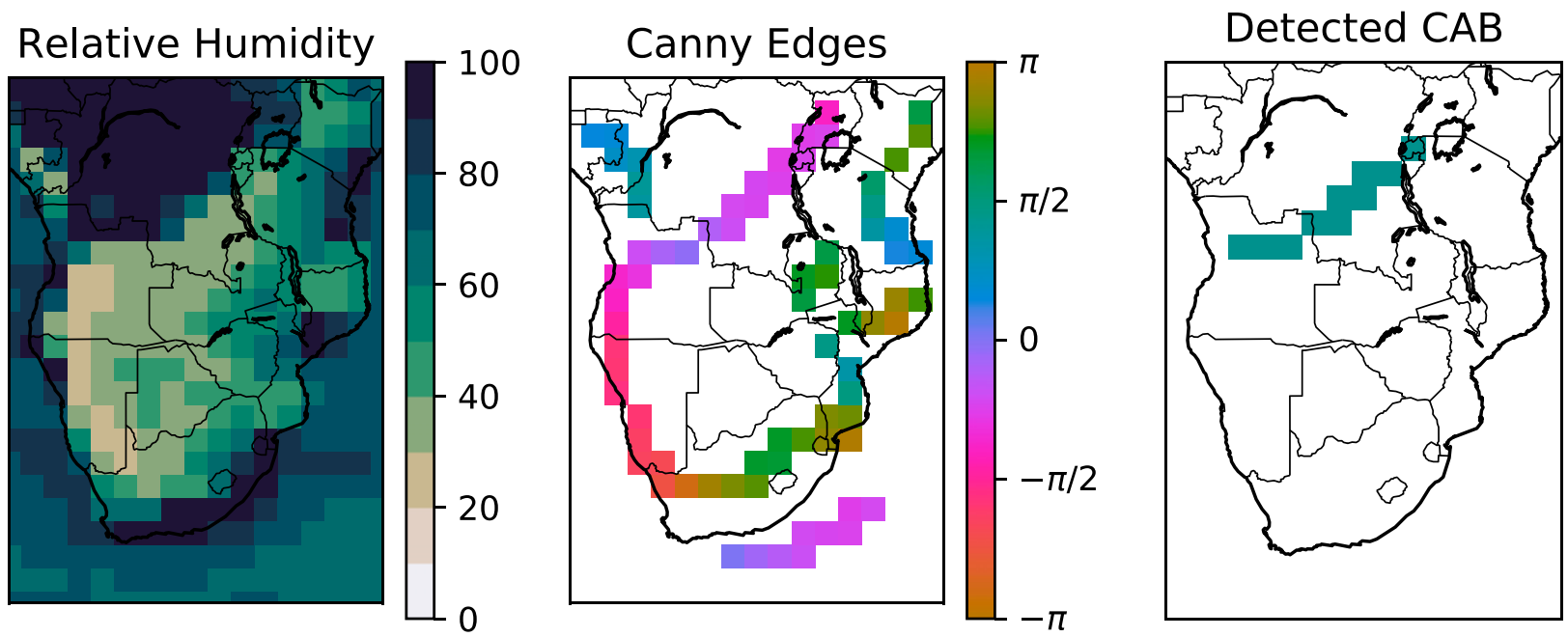

FIG. 1. (left) Surface relative humidity, (center) Canny edges, and (right) identified CAB locations on 9 Sep 1999 in ACCESS1.3.

across a Canny edge in order for a grid cell to qualify as a CAB. The center panel of Fig. 1 shows the Canny edges identified on the sample model day, colored by the orientation angle of the edge.

5) Canny edges were filtered to retain instances with $-\pi / 4<\theta<\pi / 6$ and restricted to latitudes between $5^{\circ}-18^{\circ} \mathrm{S}$.

6) At least three qualifying dryline grid cells were required to be detected at the same time in order for a $\mathrm{CAB}$ to be registered. The resultant $\mathrm{CAB}$ grid cells shown in the right panel of Fig. 1 on the sample model day.

The KD is also extracted from the calculated set of Canny edges. It is restricted to latitudes below $12^{\circ} \mathrm{S}$ and angles in the range $\pi / 6<\theta<\pi / 2$, consistent with Howard and Washington (2019). No minimum grid cell thresholds are applied in this case. As described above, three reanalysis products, ERA5, ERA-Interim, and MERRA2, have been included in this study. The thresholds described above were manually optimized so that the seasonal cycle of the relative humidity-based $\mathrm{CAB}$ in the coarsened ERA5 using the methodology of this paper was qualitatively similar to the highresolution specific humidity ERA5 results of Howard and Washington (2019).

Figure 2 shows the near-surface relative humidity and identified $\mathrm{CAB}$ points for the same case study day in early September in historical models and reanalyses. The atmospheric states on this chosen day will be in different synoptic setups. Nevertheless, a well-defined $\mathrm{CAB}$ is identified on this day in all of the CMIP5 models.

With the daily $\mathrm{CAB}$ positions calculated, climatologies of properties such as latitude, frequencies, and extent can be computed and compared. Here, the extent is calculated by counting the total number of $\mathrm{CAB}$ grid cells on a given day. This gives an approximate measure of the lateral extent of the CAB.

\section{c. Tropical lows}

The methodology used to identify tropical-low events follows Howard et al. (2019). We apply the TRACK algorithm (see Hodges 1994, 1999). The application of TRACK to CMIP5 model experiments has previously been documented by Rastogi et al. (2018) and Bengtsson et al. (2007). Howard et al. (2019) identified southern African tropical lows using 6-hourly vertical mean vorticity averaged across pressure levels at 600, 700, and $800 \mathrm{hPa}$. However, 6-hourly CMIP5 pressure-level model data were only available at 850 and $500 \mathrm{hPa}$, and so these model levels have been used instead. A comparison between the results of using this setup and using 600-, 700-, and 800-hPa daily vorticity was considered for a subset of nine models and no significant difference was found (not shown).

The data preparation algorithm was as follows. At each vertical level and for each 6-hourly time step, vertical vorticity was calculated from the zonal and meridional wind components at a T63 resolution, using the Python package windspharm. The vertical average was taken, and then a Sardeshmukh and Hoskins (1988) filter was applied to smooth the spectral cutoff. Cyclonic vorticity extrema with $\zeta<-5 \times 10^{-6} \mathrm{~s}^{-1}$ were then identified and linked using the TRACK algorithm, as detailed in Howard et al. (2019) and Hodges et al. (2017). Once these vortex tracks were identified, they were filtered for southern African tropical lows using the following criteria: 
Surface Relative Humidity and Dry-lines on the 9th of September, 1999
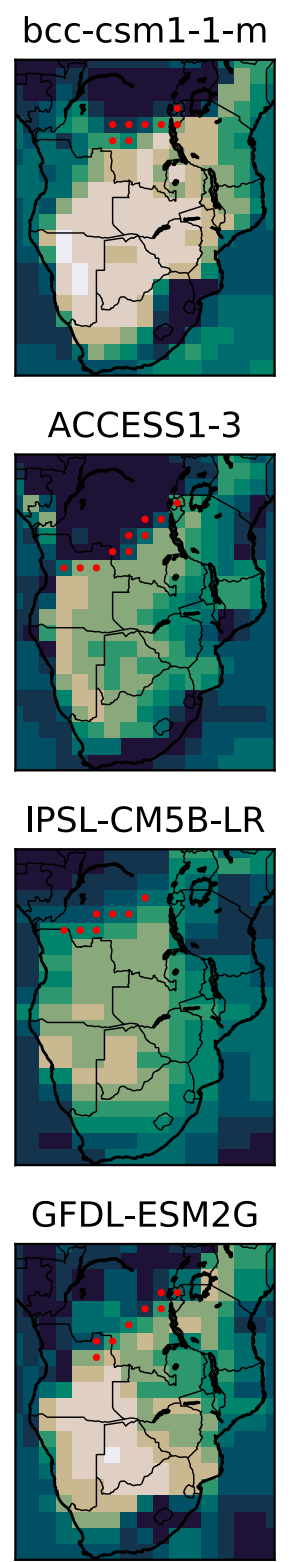

era5

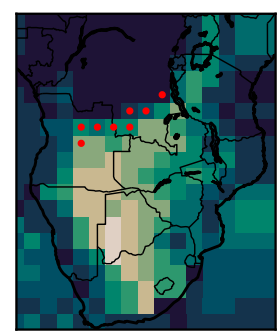

BNU-ESM

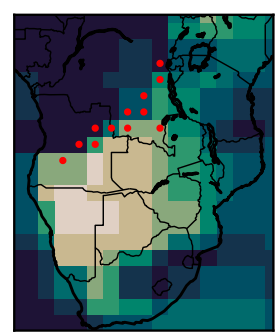

CSIRO-Mk3-6-0

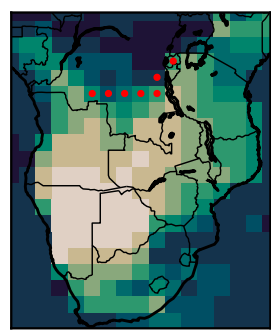

HadGEM2-CC
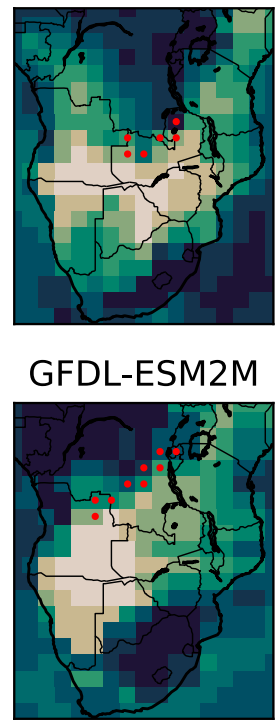

merra2

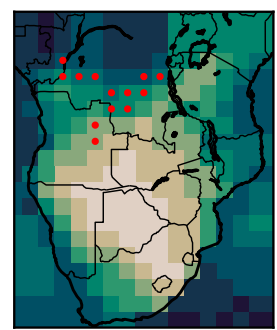

CanESM2
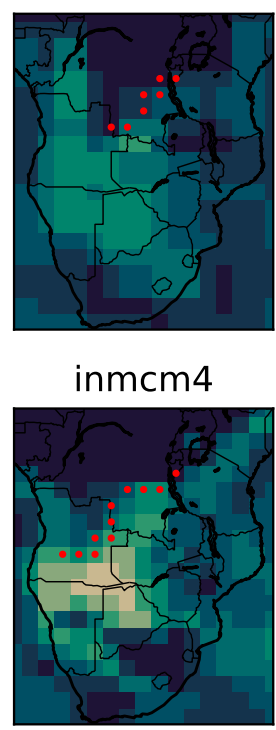

HadGEM2-ES

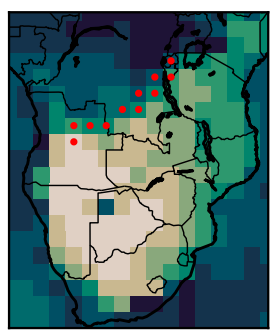

\section{CESM1-CAM5}

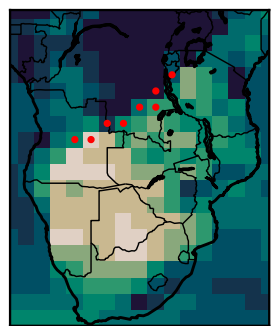

erai

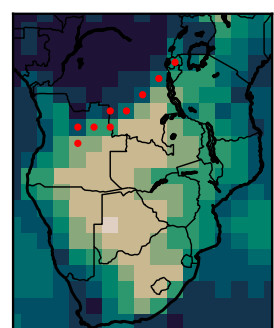

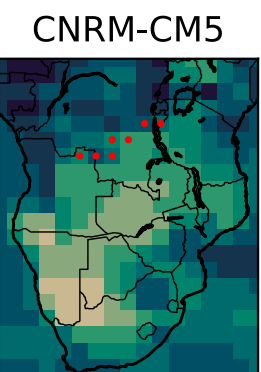
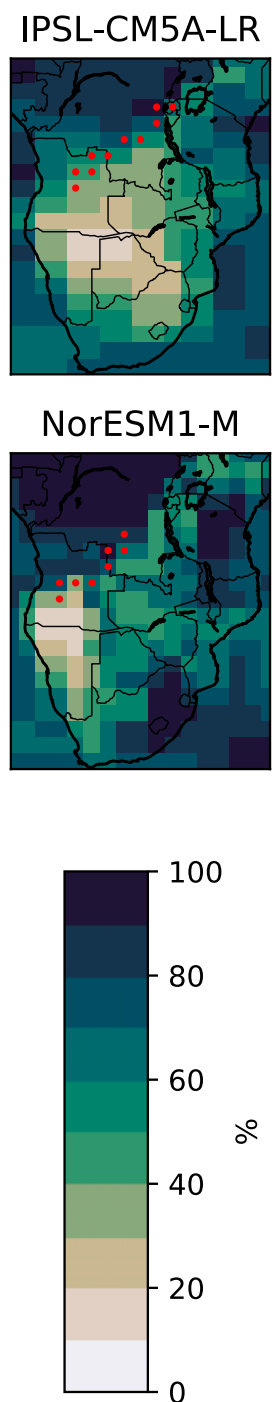

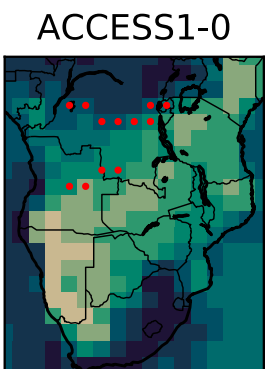

IPSL-CM5A-MR
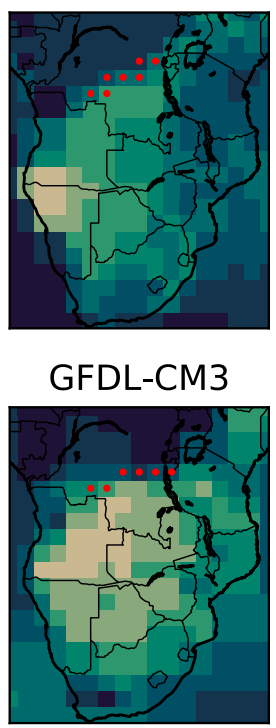

FIG. 2. Surface relative humidity (colors) and identified CAB locations (red dots) on 9 Sep 1999 in each model and reanalysis product. Surface humidity has been regridded to a $2^{\circ} \times 2^{\circ}$ grid using the nearest-neighbor method. 
1) Tracks must spend at least one time step over land;

2) Track longevity must be at least 1 day;

3) The filtered vertical mean relative vorticity must satisfy $\zeta<-3 \times 10^{-5} \mathrm{~s}^{-1}$ in at least one 6-hourly time step;

4) There must be coincident cyclonic vorticity at 500 and $850 \mathrm{hPa}$ for a continuous 24 -h period;

5) The genesis location must not be in the Atlantic; and

6) The genesis location must be north of $25^{\circ} \mathrm{S}$.

Justifications for these criteria are given in Howard et al. (2019): briefly, they exclude extratropical cyclones, coastally trapped Kelvin waves, heat lows, and spurious weak events. A sample track-longitude Hovmöller plot for each of the models and the reanalysis over one historical year is shown in Fig. 3. The models reveal a mixture of track behaviors.

Following the identification of tropical lows, rainfall is attributed to tropical lows by making the assumption that all daily rainfall that fell within a $5^{\circ}$ radius of a tropical-low centroid was attributable to that tropical low. This radius was shown to be appropriate for southern African tropical lows by Howard et al. (2019) and is consistent with many previous studies of tropical lows and tropical cyclones (Baray et al. 2003; Dare et al. 2012; Khouakhi et al. 2017; Lavender and Abbs 2013).

\section{The Congo Air Boundary}

\section{a. Representation in historical climate models}

The aim of this section is to determine whether or not the $\mathrm{CAB}$ is well represented in the CMIP5 historical simulations under consideration for the period from 1970 to 2000. Figures are designed to be comparable with the ERA5-based study of the CAB presented in Howard and Washington (2019), and modeled CAB properties are compared with the coarsened ERA5. The $\mathrm{KD}$ is also briefly considered.

Figure 4 indicates the climatological location of the $\mathrm{CAB}$ and $\mathrm{KD}$ in each climate model and reanalysis product, based on the frequency the $\mathrm{CAB}$ is detected at each interpolated $2^{\circ} \times 2^{\circ}$ grid box. It is evident that the $\mathrm{CAB}$ is detected with similar frequencies and locations in most of the models as in the reanalysis products. There is a range of variation across the models, however. CMRM-CM5, GFDL CM3, and the ACCESS models show concentrated, high-intensity CAB locations with a diagonal orientation from west of Lake Victoria through to southwest Angola. NorESM1-M and BCC-CSM1.1m show heat maps with a distinct north and south peak. All three IPSL models show low CAB detection frequencies in the east. This is particularly interesting since the IPSL-CM5A models have previously been shown to be outliers in East Africa, lacking the moisture-rainfall relationship present in most other models (Rowell and Chadwick 2018). CanESM2 exhibits lower-frequency $\mathrm{CAB}$ detection rates than the other models, suggesting that it may struggle to represent the feature. The biases of the spatial distribution of the CAB in these climate models relative to ERA5, and their significance relative to natural variability over the 30 -yr time period, are shown in Fig. S2. Overall, climate models exhibit biases that are larger than the variability across the reanalysis products. However, the reanalysis products do display some differences, particularly in the locations of peak CAB detection.

There is much more variability in the representation of the KD in CMIP5 models. BNU-ESM shows a very persistent KD, while CSIRO-Mk3.6 and GFDL models represent it reasonably well and some other models, such as CNRM-CM5 and CanESM2, miss it completely. Meanwhile, MERRA-2 shows a more infrequent KD than the other reanalysis products. We conclude that the $\mathrm{KD}$ is not as well represented in CMIP5 models as the $\mathrm{CAB}$, and postpone further analysis for a future study.

We next study the seasonal cycle of key CAB features in the CMIP5 models. The seasonal cycles of the CAB latitude, frequency, and extent in CMIP5 models and low-resolution reanalysis products are shown in Fig. 5. The CAB latitude and extent are both calendar day climatological means between 1970 and 2000, and all variables have been smoothed by a 2 -week running mean. The extent is calculated by counting the total number of $\mathrm{CAB}$ grid cells on a given climatological day of the year. Only the days when a CAB was identified were used in the average. This gives an approximate measure of the lateral extent of the $\mathrm{CAB}$, although it is not precisely comparable across CABs of different orientations. The latitude shown is the mean latitude of all $\mathrm{CAB}$ points on a given day, and the frequency is the proportion of days at a given time of year where a $\mathrm{CAB}$ is present.

Howard and Washington (2019) found that based on ERA5, the CAB moves steadily southward between the start of August and the end of November, and that its detection frequency drops from near $100 \%$ at the start of October to $10 \%-20 \%$ at the beginning of December. In the present study, similar behavior is present in the latitude and frequency (top and middle panels respectively of Fig. 5). The rate at which the CAB moves south is close to constant across models and consistent with ERA5, at roughly $2^{\circ}$ (month) $)^{-1}$. Results from ERA5 are located at the southern edge of the CMIP5 simulated range. At any given time of the year, the climatological $\mathrm{CAB}$ latitude has a range of $5^{\circ}$. Since this range is of a similar order of magnitude to the Nyquist frequency 


\section{Track Longitudes in 1986-1987}
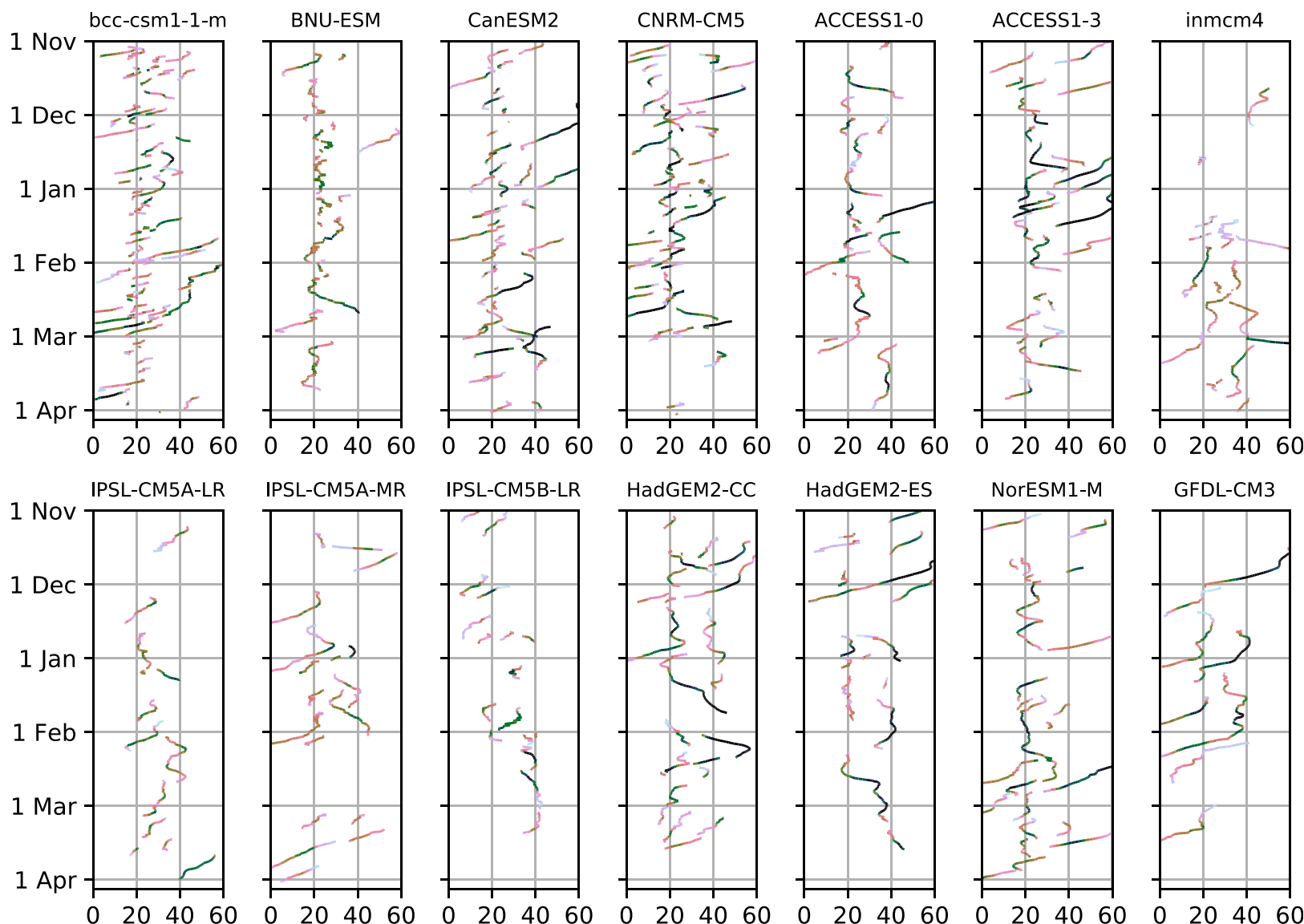

HadGEM2-CC

HadGEM2-ES
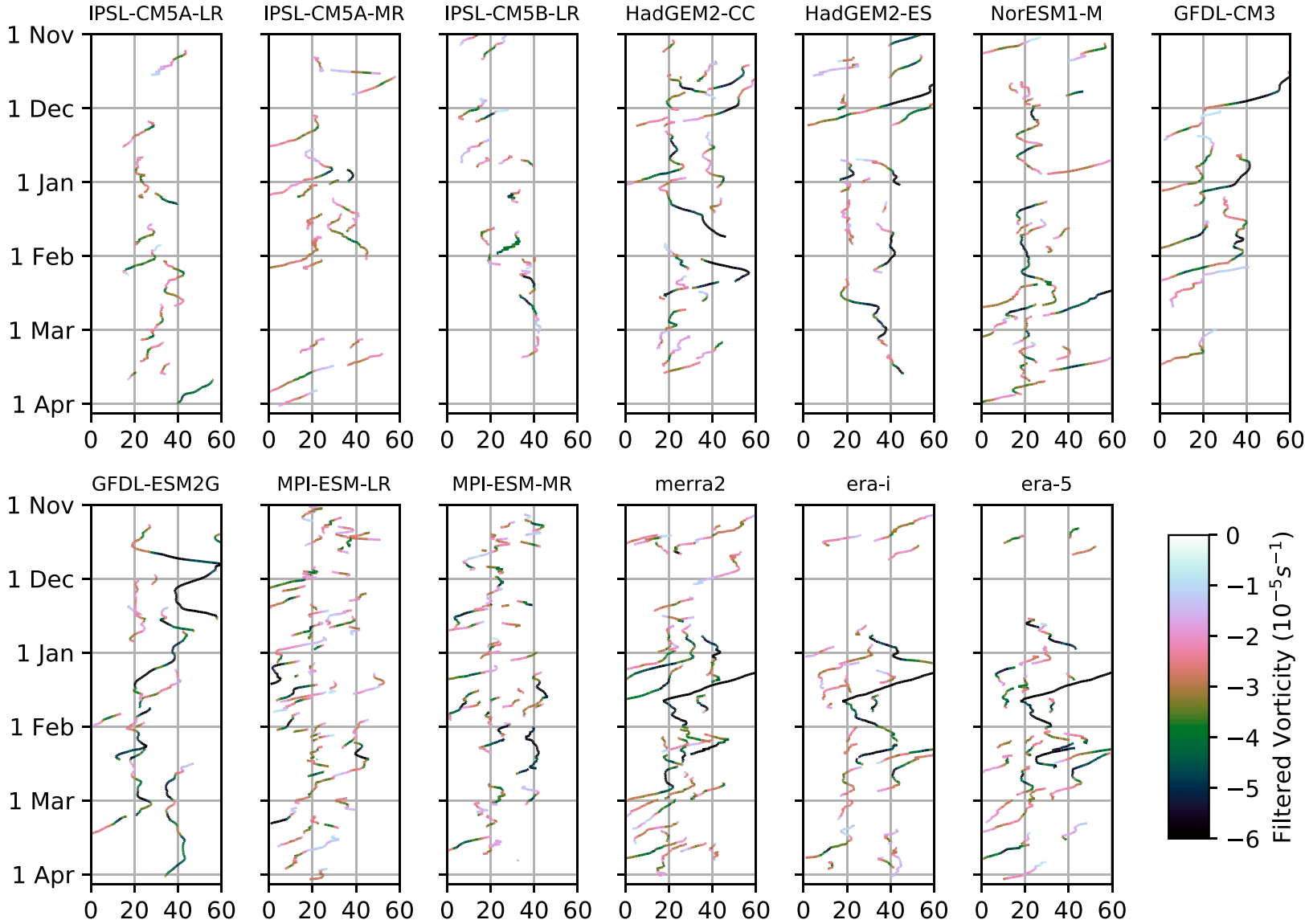

FIG. 3. Tropical-low track Hovmöller plots for each model and reanalysis product ( $x$ axis: longitude, $y$ axis: time). Colors indicate the T63 filtered vorticity of the tropical-low event, a measure of the event intensity.

$\left(2 \Delta x=4^{\circ}\right)$, we surmise that the CAB latitude is represented in these models as well as can be expected. Based on the center panel of Fig. 5, it is evident most models, as well as MERRA-2, show a decreased CAB frequency in August; however, all models except CAN-ESM2 recover by early September and the vast majority possess
$\mathrm{CABs}$ that are present $80 \%$ of the time. The $\mathrm{CAB}$ breaks down between October and December in all models, with ERA5 breaking down later than the ensemble mean but being located well within the model range. The ensemble-mean $\mathrm{CAB}$ extent peaks at the beginning of October, consistent with the discontinuity 
Proportion of days with CAB or KD identified at each grid point

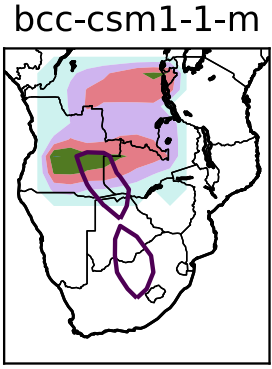

ACCESS1-3

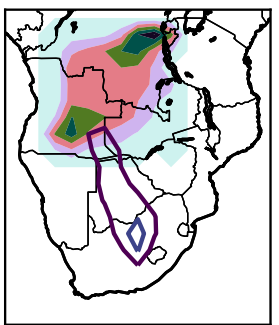

IPSL-CM5B-LR

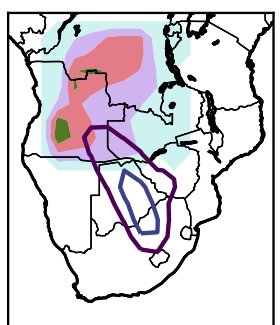

GFDL-ESM2G

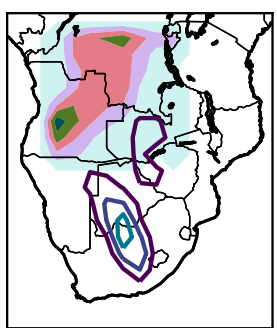

era5

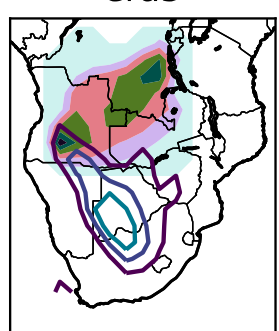

BNU-ESM

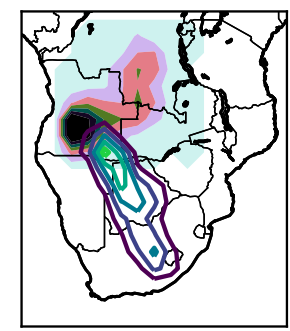

CSIRO-Mk3-6-0

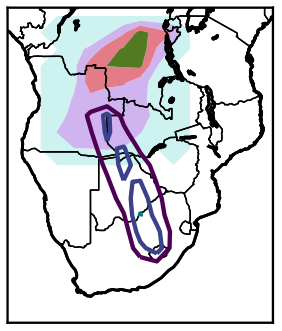

HadGEM2-CC

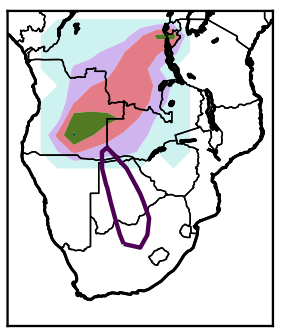

GFDL-ESM2M

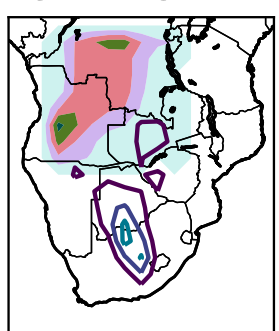

merra2

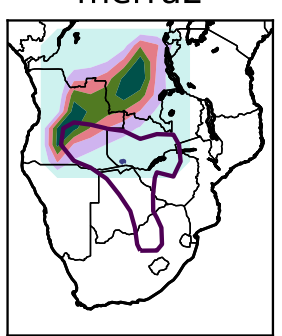

CanESM2

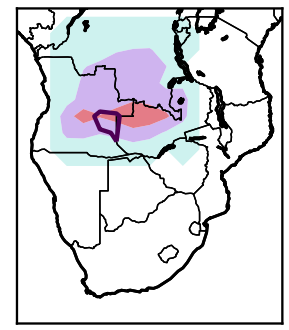

inmcm4

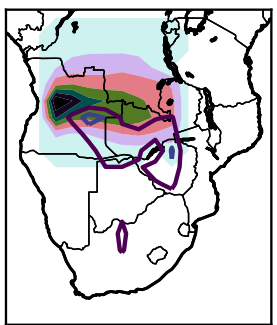

HadGEM2-ES

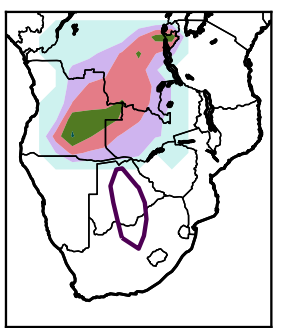

CESM1-CAM5

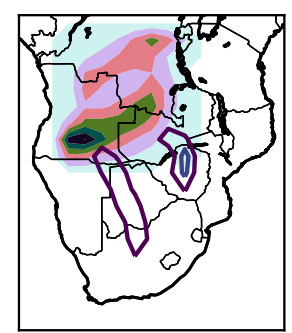

erai

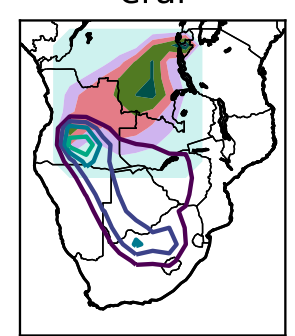

CNRM-CM5

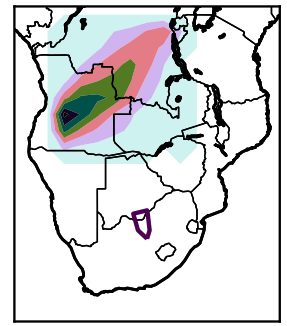

IPSL-CM5A-LR

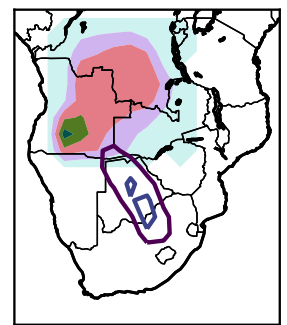

NorESM1-M
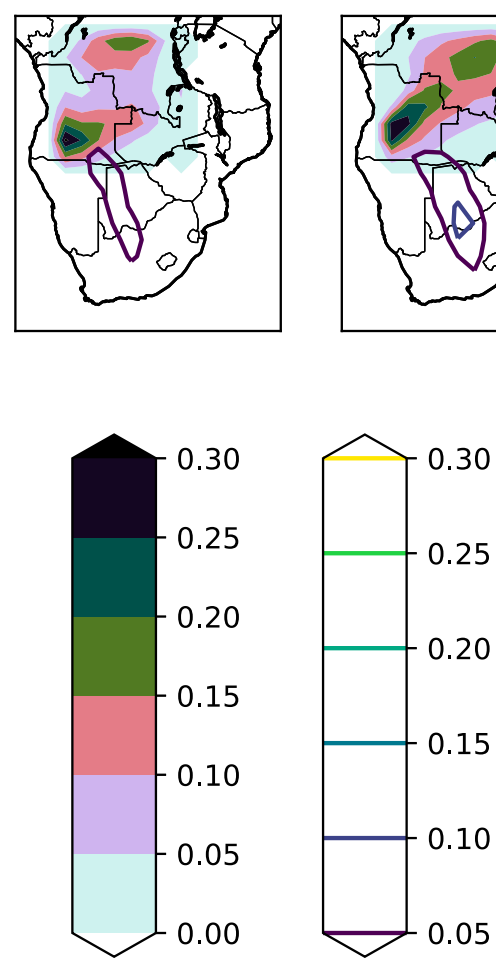

ACCESS1-0

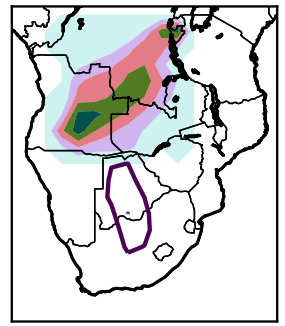

IPSL-CM5A-MR

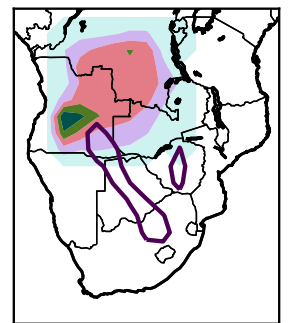

GFDL-CM3

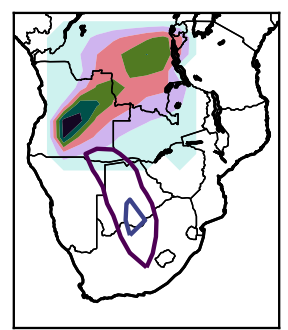

0.30

0.25

20

0.15

0.10

0.05

FIG. 4. Spatial distributions of CAB and KD frequency (number of events per interpolated grid cell per year). Filled contours indicate hte $\mathrm{CAB}$. Line contours indicate the KD. Panels shows results from different models and reanalysis products. 


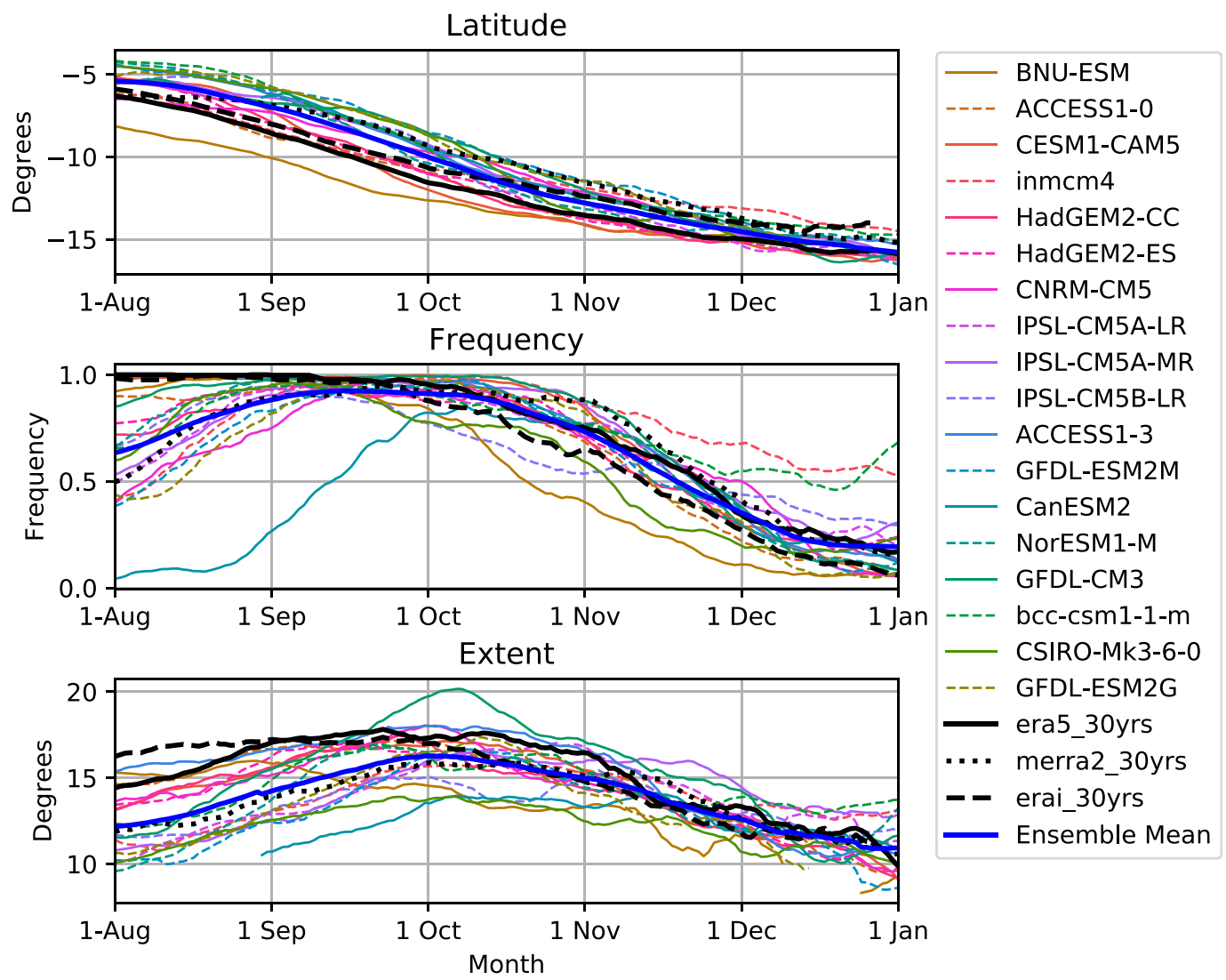

FIG. 5. Seasonal cycles of CAB properties: (top) mean CAB latitude, (middle) CAB frequency, and (bottom) $\mathrm{CAB}$ extent (number of grid cells identified per day). Thin colored lines indicate models, and are ordered by the mean $\mathrm{CAB}$ latitude averaged from August to November. Black lines show reanalysis products; thick blue lines show the ensemble mean. All quantities are smoothed by a 2 -week running mean.

width presented by Howard and Washington (2019) (their Fig. 5). The reanalysis spread in the seasonal cycles of these metrics is approximately half of the model spread.

Based on the above analysis we conclude that the $\mathrm{CAB}$ is well represented in most of the climate models considered, with the exception being CanESM2. We therefore proceed to study the change in the $\mathrm{CAB}$ between present-day and future climate models, and to assess the impact of this change on rainfall in southern Africa under the RCP8.5 scenario.

\section{b. Future change and rainfall implications}

In this section, we explore how the CAB changes in the future and whether these changes are linked to projected southern African drying. Figure 6 shows the difference, in each model, between the CAB latitude, frequency, and extent in the RCP8.5 end-oftwenty-first-century simulation and in the historical end-of-twentieth-century simulation. The main change is an increase in the $\mathrm{CAB}$ frequency from October to December, peaking at approximately $25 \%$ in GFDL-CM3 and averaging to $13 \%$ in the ensemble mean. This frequency increase is accompanied by a northward shift in CAB latitude on average of $0.7^{\circ}$. These changes are significant relative to natural variability in between 11 and 15 of the 18 models across the three months, as shown in the bottom panel of Fig. 6. This indicates that the gradual southward progression and seasonal frequency decline of the $\mathrm{CAB}$ is delayed in most climate models, and so the $\mathrm{CAB}$ becomes more frequent toward the end of the season. Further analysis (not shown) indicates that the delay in $\mathrm{CAB}$ breakdown is approximately half a month. During this period, there is an increase in the $\mathrm{CAB}$ extent, which is significantly different from 0 as compared to model spread at the $p<$ 0.05 level in November and December, and compared to natural variability in 12 models.

$\mathrm{CAB}$ frequency is also decreased in mid-August in most models and the ensemble mean. This is the same period when the $\mathrm{CAB}$ frequency was not well represented in Fig. 5. This frequency decline may be related to the anomalous representation of the $\mathrm{CAB}$ in August. 


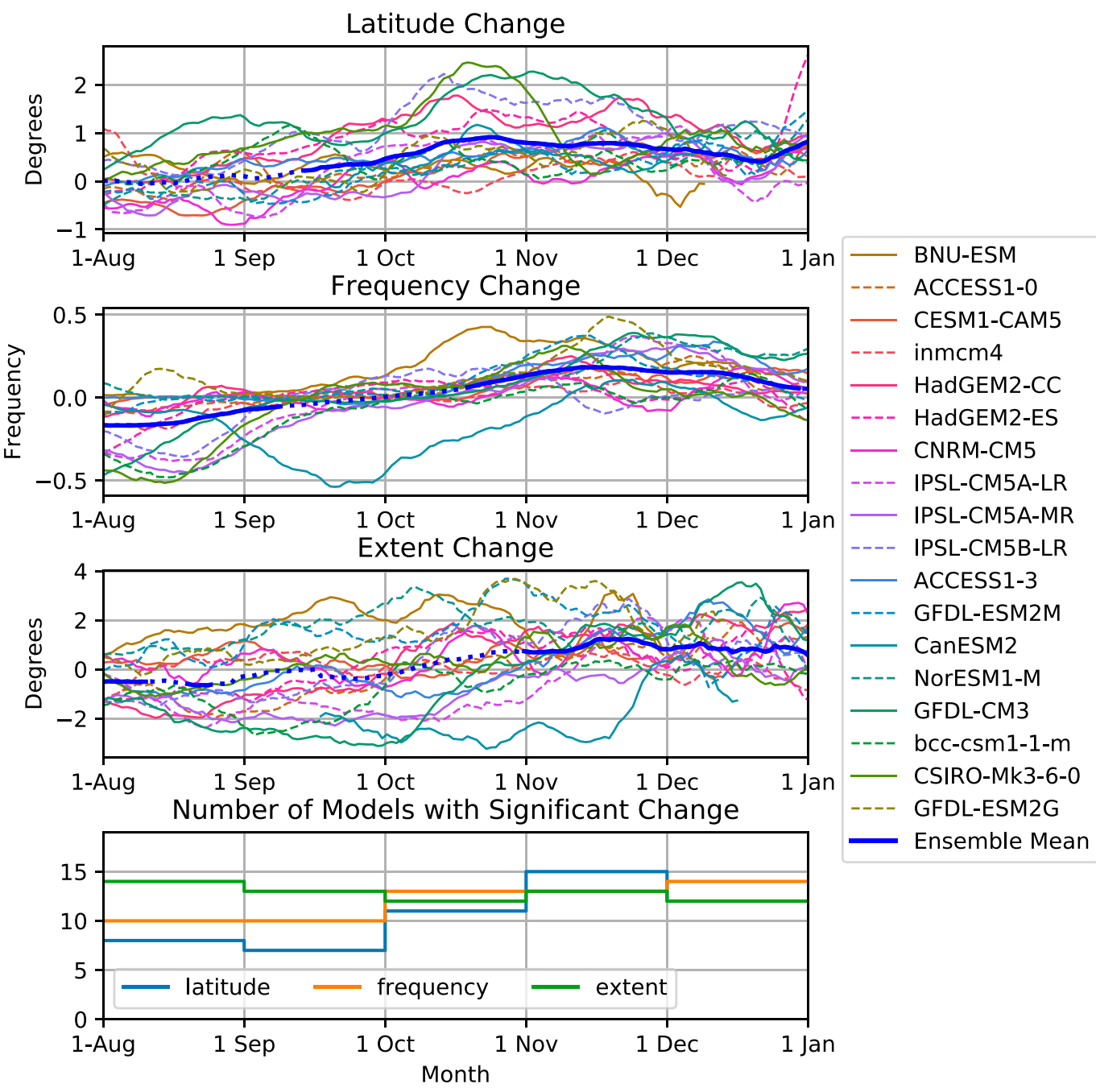

FIG. 6. Seasonal cycles of future change of CAB properties. As in Fig. 5, but showing the average of each property for the RCP8.5 end-of-twenty-first-century scenario minus that for the historical end-of-twentieth-century scenario. The thick blue line indicates the ensemble mean and is shown as a solid line when the ensemble mean is significantly different from zero at the $p<0.05$ level using a paired $t$ test, and as a dotted line otherwise. All quantities are smoothed by a 2 -week running mean. (bottom) The number of models for which the future change signal is significant against internal variability at the $p<0.05$ level for each month, using a Welch's $t$ test. Colors are ordered as in Fig. 5. Colors in the top three panels are ordered as in Fig. 5.

Most models return to displaying historical CAB frequencies by September, with the exception of CanESM2, whose $\mathrm{CAB}$ was shown earlier to be poorly represented in historical simulations.

Howard and Washington (2019) found that the interannual CAB frequency was anticorrelated with precipitation between $10^{\circ}$ and $15^{\circ} \mathrm{S}$ in October, November, and December. Since the October-December CAB frequency increases in most CMIP5 models considered in this study, it seems plausible that this increase may be linked to the projected rainfall decline present in most models. To explore this further, we decompose daily OND rainfall at each grid cell into three components:
1) North-of-CAB rain: rain that fell at a grid cell that was in the same longitude band as an identified CAB dryline, with the grid cell located to the north of the dryline;

2) South-of-CAB rain: rain that fell at a grid cell that was in the same longitude band as an identified $\mathrm{CAB}$ dryline, with the grid cell located to the south of the dryline; and

3) CAB-breakdown rain: rain that fell at a grid cell for which no $\mathrm{CAB}$ drylines were detected in the same longitude band.

The top row of Fig. 7 shows the decomposition of the historical climatological mean OND rainfall into these 
Historical OND Rainfall
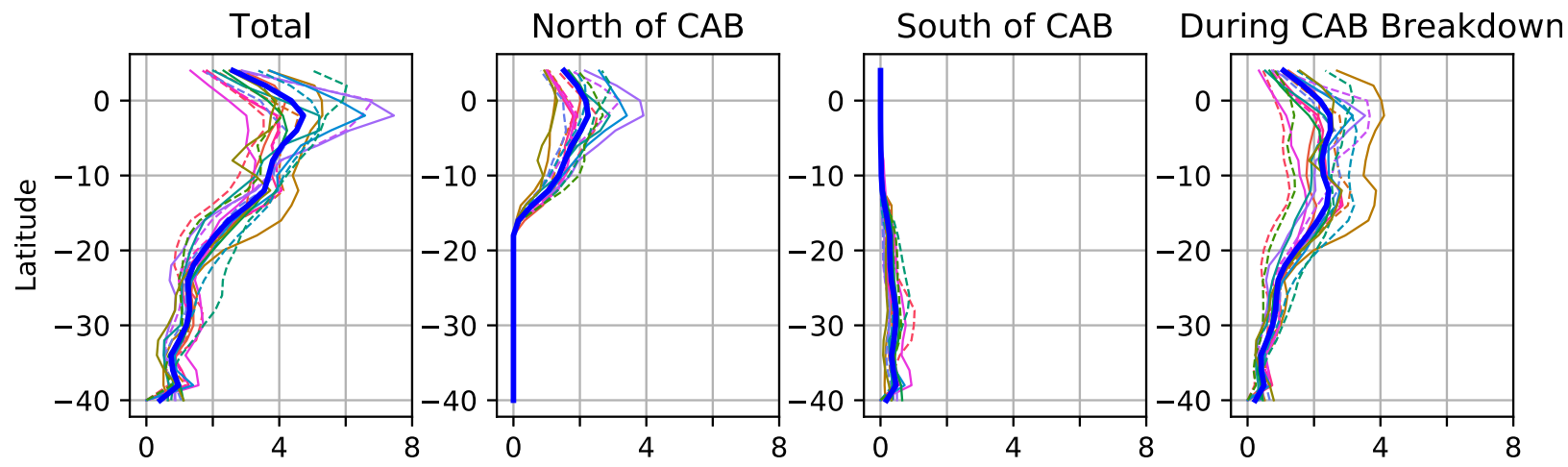

Change in OND Rainfall
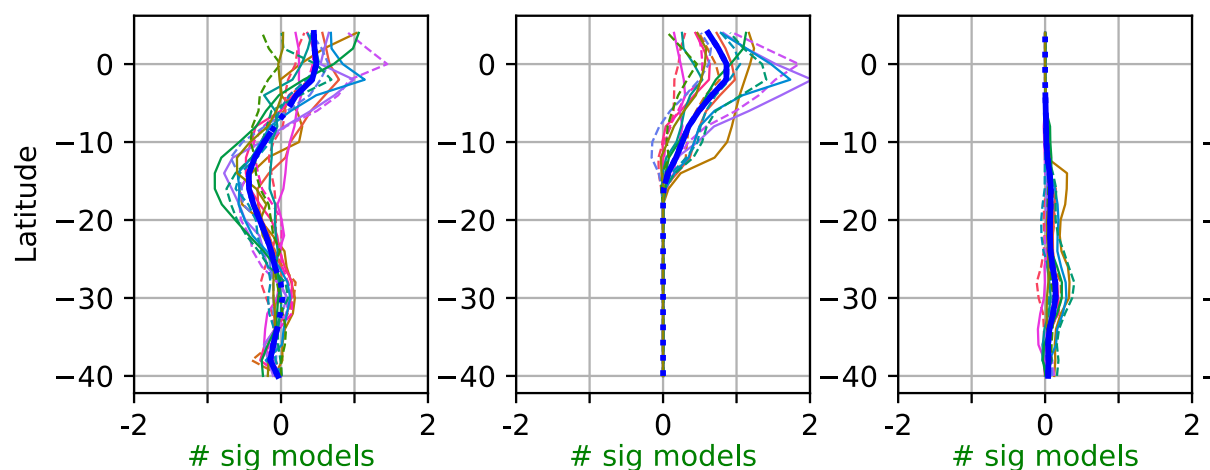

10

\# sig models

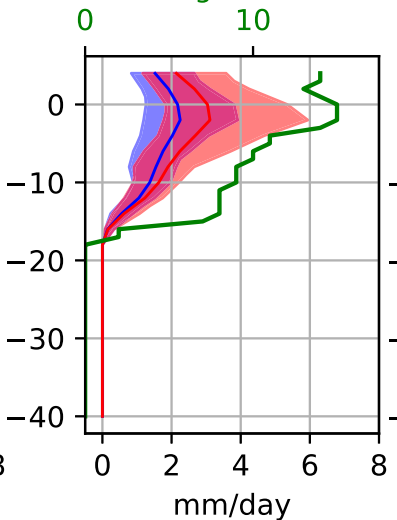

$\mathrm{mm} /$ day

HadGEM2-ES

CNRM-CM5

IPSL-CM5A-LR

IPSL-CM5A-MR IPSL-CM5B-LR

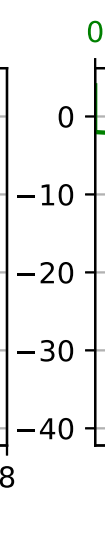

$0 \quad 10$ $\mathrm{mm} / \mathrm{day}$
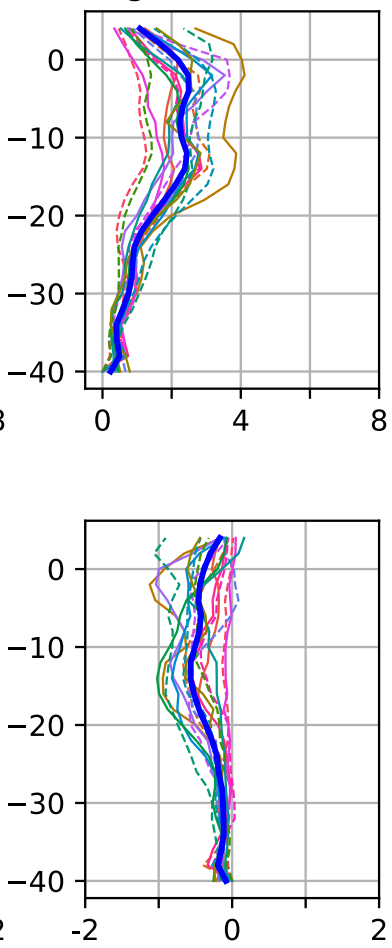

\# sig models

10
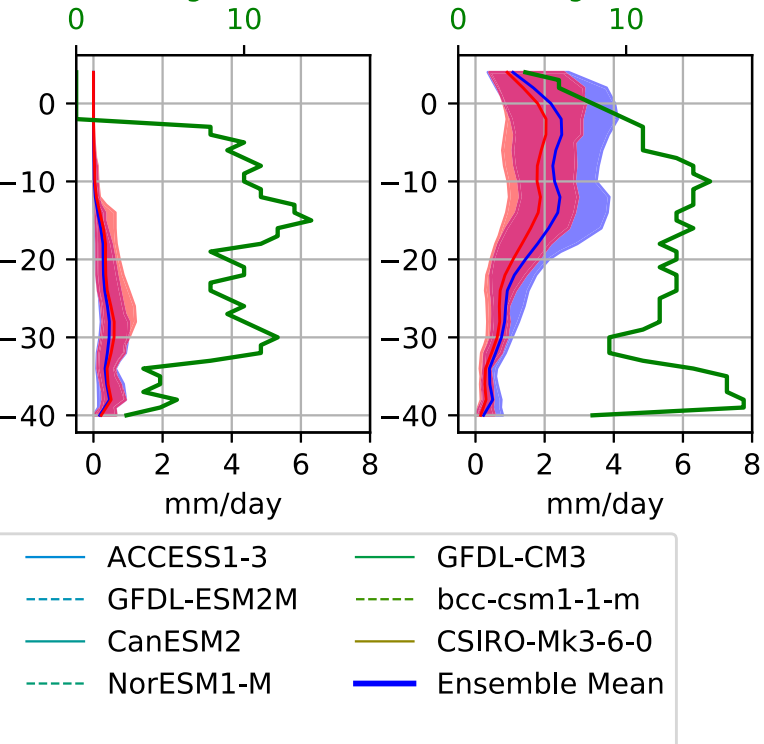

FIG. 7. CAB rainfall decomposition. (top) Historical rainfall. (middle) RCP8.5 minus historical. (bottom) Comparison of the intermodel spread in historical (blue) and RCP8.5 (red) simulations, showing the number of models that exhibit a significant change relative to interannual variability at the $p<0.05$ level, based on a paired $t$ test (green line, top-axis labels). Columns show (left to right) total rain and rainfall that falls north of the $\mathrm{CAB}$, south of the $\mathrm{CAB}$, and during $\mathrm{CAB}$ breakdown. All panels show the October-December mean. Colors are ordered as in Fig. 5. 
three categories, as a function of latitude and averaged over longitudes between $20^{\circ}$ and $30^{\circ} \mathrm{S}$. As predicted, the rainfall to the south of the $\mathrm{CAB}$ is small, and is only comparable to the total rainfall at subtropical latitudes $\left(30^{\circ}-40^{\circ} \mathrm{S}\right)$. Rainfall at tropical latitudes, between $0^{\circ}$ and $15^{\circ} \mathrm{S}$, is evenly distributed between the remaining two categories. North-of-CAB rainfall is identically zero south of $18^{\circ} \mathrm{S}$, as the $\mathrm{CAB}$ does not extend south of this point.

The division of rainfall into these three components is based on the hypothesis, proposed by Howard and Washington (2019), that the CAB largely prevents tropical rain to its south and that the primary means by which spring rainfall occurs in southern Africa is a full or partial breach in the CAB. Thus component 2-rainfall south of the $\mathrm{CAB}$ - is expected to be small and primarily of extratropical origin. Component 1 is rainfall associated with "Congo Air" in the deep tropics, and component 3 is rainfall associated with tropical temperate troughs (TTTs) and other CAB-breakdown events. This decomposition does not account for the fact that a grid cell associated with an elongated TTT may exist to the south of a CAB grid cell due to the TTT's diagonal structure. However, this limitation does not appear to be significant, based on the calculated low magnitude of rain to the south of the CAB in Fig. 7.

Meanwhile, the middle row of Fig. 7 shows the future change of each category of rainfall. The change in the total rainfall shows the familiar dipole structure, with most models showing drying south of $10^{\circ} \mathrm{S}$ and either wetting or a comparatively low magnitude of drying north of $5^{\circ} \mathrm{S}$. The decomposition into rainfall classifications is enlightening: there is an increase in rainfall to the north of the $\mathrm{CAB}$, and a decrease in rainfall coming from the CAB-breakdown events. In each case the direction of change is remarkably robust between models and across latitudes.

To provide further visualization of the projected change, the bottom row of Fig. 7 shows the envelopes indicating the model spread of rainfall projections in historical (blue) and RCP8.5 (red) simulations. Change in the rainfall decomposition terms is more pronounced than change in the total rainfall. The green line in these figures indicates the number of models that show a significant change relative to natural variability. At least 13 of the 18 models show a significant decline in CAB breakdown rainfall between $8^{\circ}$ and $28^{\circ} \mathrm{S}$.

This implies that the ensemble-mean OND drying and rainfall change dipole is associated with the change in the $\mathrm{CAB}$ frequency. The drying is fully contained within the component of the rainfall that falls on CAB breakdown days, while the wetting occurs to the north of the CAB. The rainfall rate per CAB-breakdown day and or north of $\mathrm{CAB}$ rainfall per $\mathrm{CAB}$ day was also considered, but no consensus on the sign of change was apparent (not shown). The projected decrease in rainfall on non$\mathrm{CAB}$ days and increase in rainfall to the north of the $\mathrm{CAB}$ is therefore directly linked to the projected increase in the frequency of CAB days. The spatial patterns of the ensemble-mean change of OND rainfall under this decomposition, shown in the top row of Fig. 8, are consistent with this conclusion.

Furthermore, intermodel spread of the projected $\mathrm{CAB}$ frequency increase explains a large proportion of the projected southern African drying. This is shown in the bottom row of Fig. 8, which show the intermodel regression of OND model rainfall change (averaged over $5^{\circ}-25^{\circ} \mathrm{S}, 15^{\circ}-30^{\circ} \mathrm{E}$ ) against the modeled CAB frequency change. $\mathrm{CAB}$ frequency change is averaged over November and December, the months in which the ensemble-mean change is significant. Before the CAB rainfall decomposition is applied, $46 \%$ of the intermodel variation of total OND rainfall change is explained by intermodel variation in the $\mathrm{CAB}$ frequency change. Variation in the rainfall decline during CAB-breakdown events is more strongly predicted by variation in the CAB latitude change $\left(R^{2}=0.71\right)$. While the CanESM2 data point (blue-green circle) appears to have a large degree of leverage in these regressions, its exclusion did strongly not impact the significance of the results (not shown).

Taken together, these results imply that the OND rainfall decline signal in southern Africa is largely explained by the increased frequency of the CAB, which prevents $\mathrm{CAB}$-breakdown-associated rainfall in the regions that are located to the south of the CAB. Between $5^{\circ}$ and $15^{\circ} \mathrm{S}$, this comes with an increase in rainfall on $\mathrm{CAB}$ days, as parts of this region are often located to the north of the CAB.

\section{Tropical lows}

We now shift focus to tropical lows, cyclonic vortices that form in the austral summer and have been found to deliver $31 \%$ of summer rainfall to the tropical edge region $\left(16^{\circ}-22^{\circ} \mathrm{S}\right)$ of southern Africa (Howard et al. 2019). Tropical lows tend to cluster in Angola and western Zambia, where they form the synoptic expression of the late-summer tropical-low phase of the climatological Angola low (Howard and Washington 2018). This section first examines the representation of tropical lows in 18 CMIP5 models. We then consider their contribution to precipitation and future change.

\section{a. Representation in historical climate models}

To evaluate the representation of tropical lows in CMIP5 models, we first consider climatological spatial 


\section{Ensemble mean rainfall change (OND)}
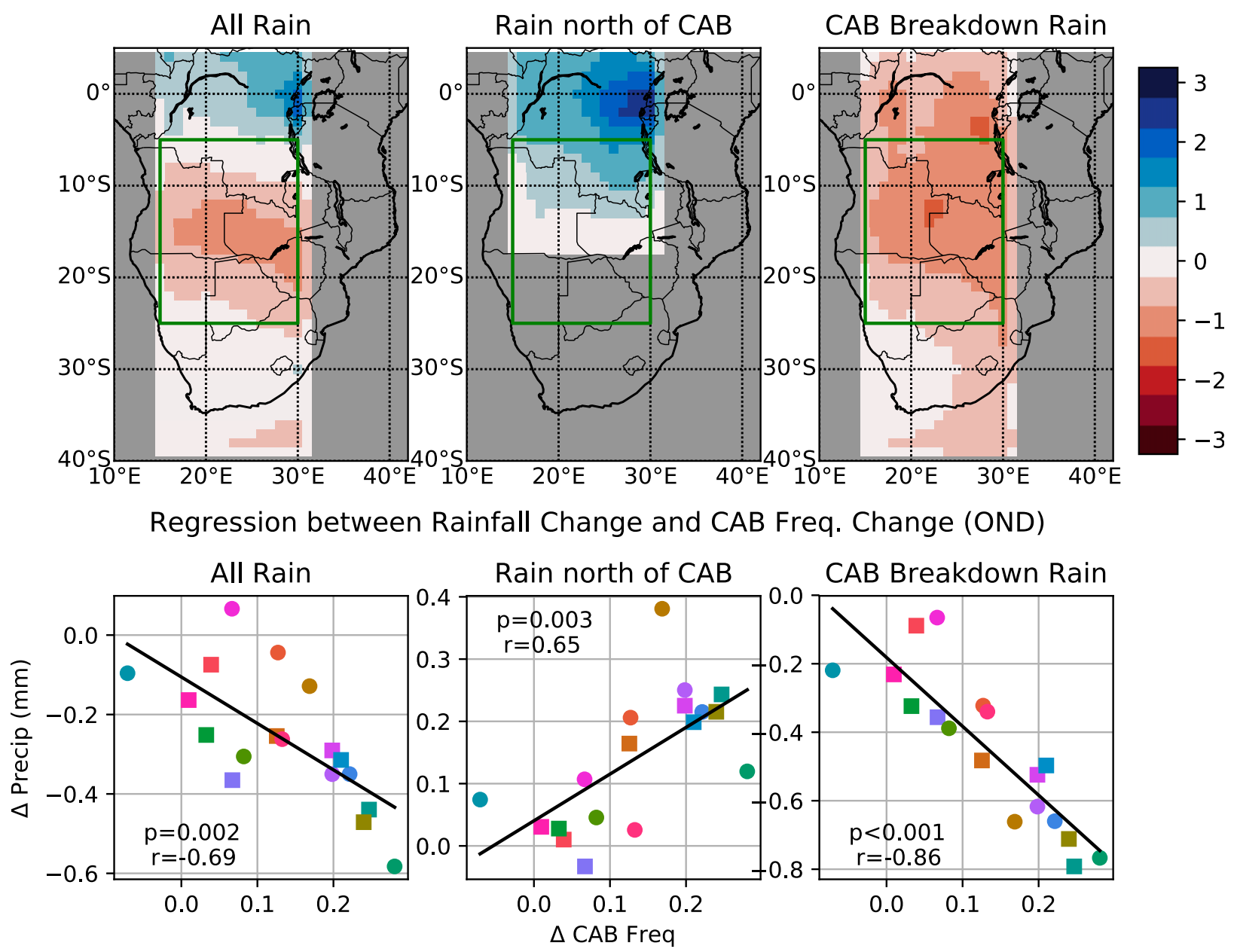

\begin{tabular}{|lllllll}
\hline BNU-ESM & HadGEM2-ES & $\bullet$ & ACCESS1-3 & $\bullet$ & GFDL-CM3 \\
ACCESS1-0 & $\bullet$ & CNRM-CM5 & $\square$ & GFDL-ESM2M & $\square$ & bcc-CSm1-1-m \\
CESM1-CAM5 & $\square$ & IPSL-CM5A-LR & $\bullet$ & CanESM2 & $\bullet$ & CSIRO-Mk3-6-0 \\
inmcm4 & $\bullet$ & IPSL-CM5A-MR & $\square$ & NorESM1-M & $\square$ & GFDL-ESM2G \\
HadGEM2-CC & HPSL-CM5B-LR & & & &
\end{tabular}

FIG. 8. (top) Ensemble-mean rainfall change OND based on CAB decomposition. (bottom) Linear regression between rainfall OND change in the region $5^{\circ}-25^{\circ} \mathrm{S}, 15^{\circ}-30^{\circ} \mathrm{E}$ and the November-December CAB frequency change. The black line is a least squares regression. The text in the bottom row includes the $p$ value for the test that the slope of the regression is equal to zero and Pearson's correlation coefficient. Values are shown for (left) total rainfall, (center) rain that occurs north of the $\mathrm{CAB}$, and (right) rain that occurs during $\mathrm{CAB}$ breakdown events. Colors are ordered as in Fig. 5.

distributions of tropical-low locations, shown in Fig. 9. From this figure, it is evident that most models get the broad shape of the distribution of tropical lows correct, with a maximum occurring in eastern Angola, the locus of the Angola tropical low. There is a wide range in the number of strong tropical-low events per year. Most models show a lower count of tropical-low days per year than MERRA-2 and ERA5, while ERA-Interim is roughly in the middle of the model distribution. This stands in contrast to the findings of Munday and Washington (2017), who report that the geopotential height anomaly associated with the Angola low is overrepresented in CMIP5 models, although they did not consider ERA5 or MERRA-2 for comparison. 
Number of tropical low days per year for each $2 \times 2$ degree box

bcc-csm1-1
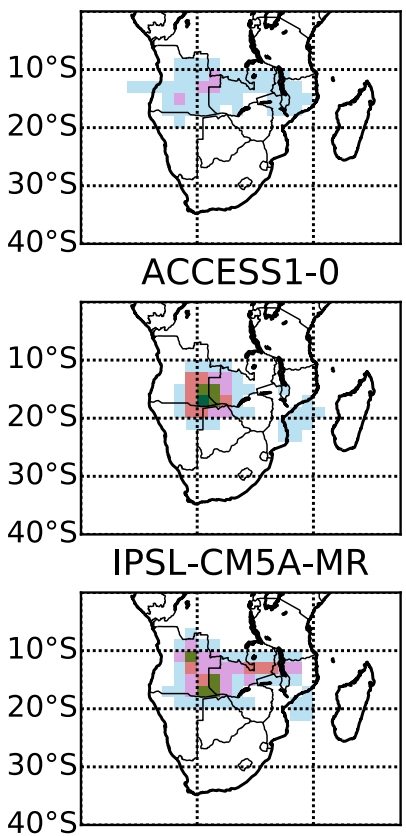

NorESM1-M

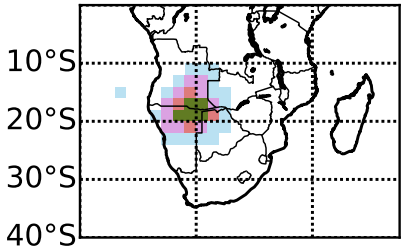

MPI-ESM-MR
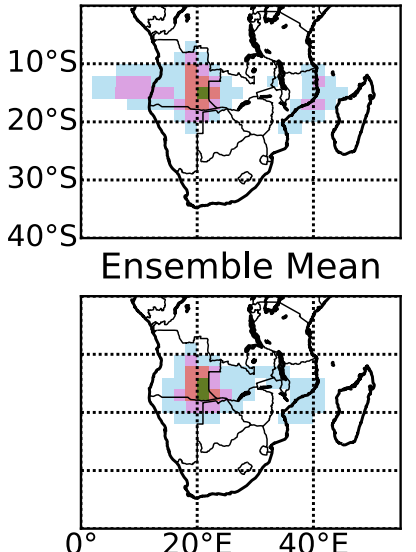

BNU-ESM

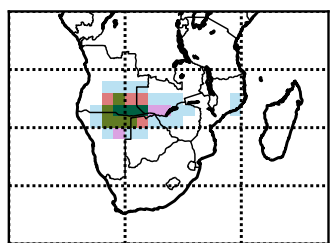

ACCESS1-3

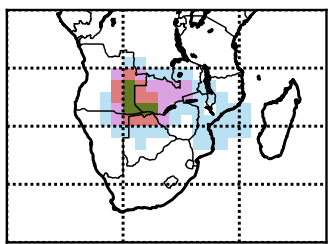

IPSL-CM5B-LR

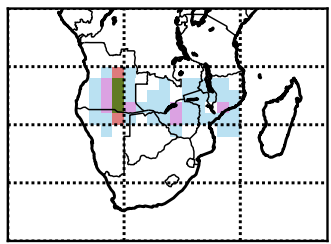

GFDL-CM3

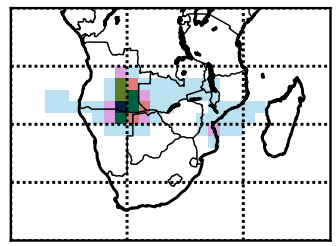

merra2
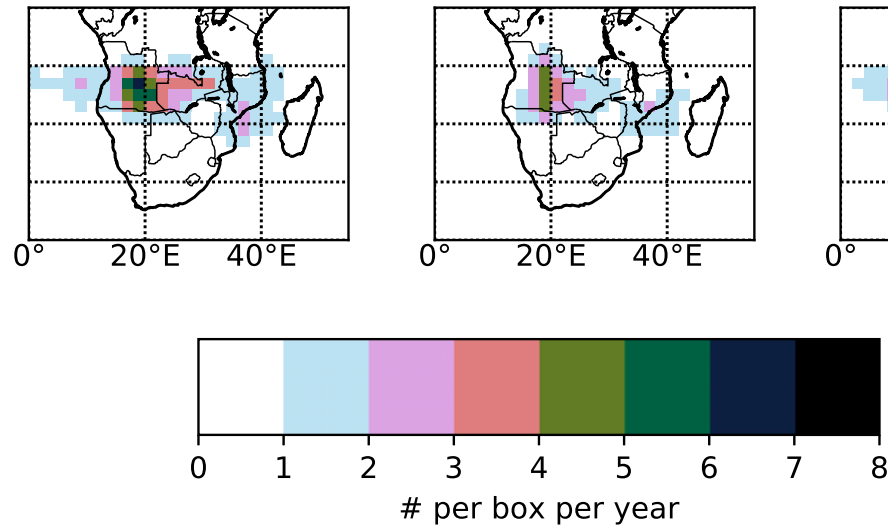

CNRM-CM5

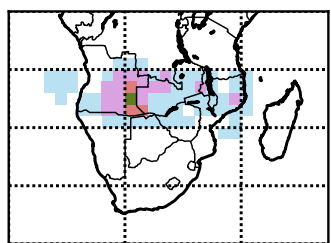

inmcm4

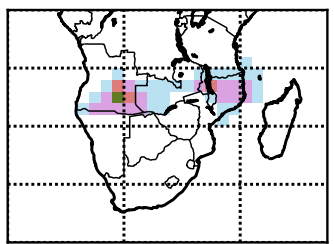

HadGEM2-CC

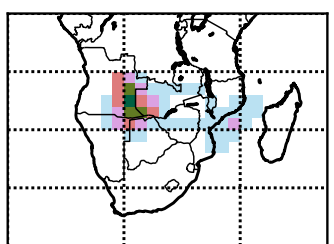

GFDL-ESM2G

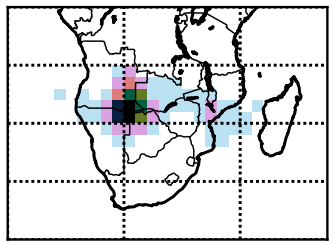

era-i

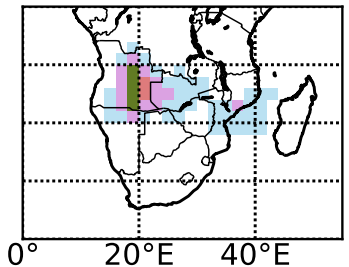

IPSL-CM5A-LR

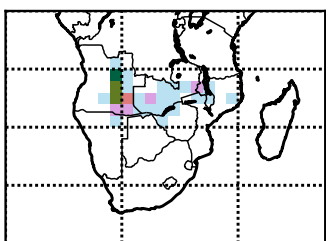

HadGEM2-ES

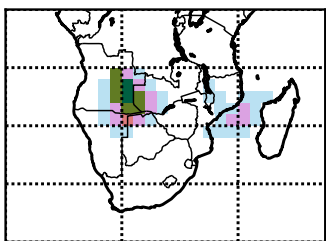

MPI-ESM-LR

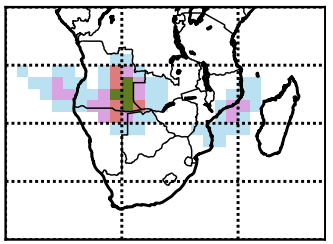

era-5

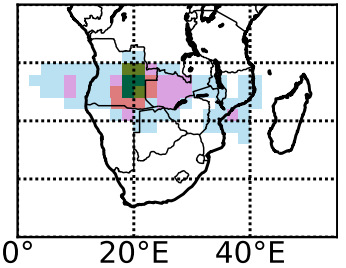

FIG. 9. Spatial distributions of tropical lows per $2^{\circ} \times 2^{\circ}$ grid cell. Panels indicate different models, the ensemble mean, and reanalysis products.

However, we do find that two models that have the most prevalent tropical lows (ACCESS1.3 and GFDLESM2G) also had strong geopotential height anomalies according to Munday and Washington (2017). The spread of tropical-low characteristics between the three reanalysis products was studied in detail by Howard et al. (2019), and is typically reduced compared to the model spread.

The tropical-low latitudes are shifted overly southward toward the western edge of the Namibian Caprivi strip $\left(18^{\circ} \mathrm{S}, 20^{\circ} \mathrm{E}\right)$ in most models, notably BNU-ESM, CNRMCM5, INM-CM4, NorESM1-M, and HadGEM2-CC. The 

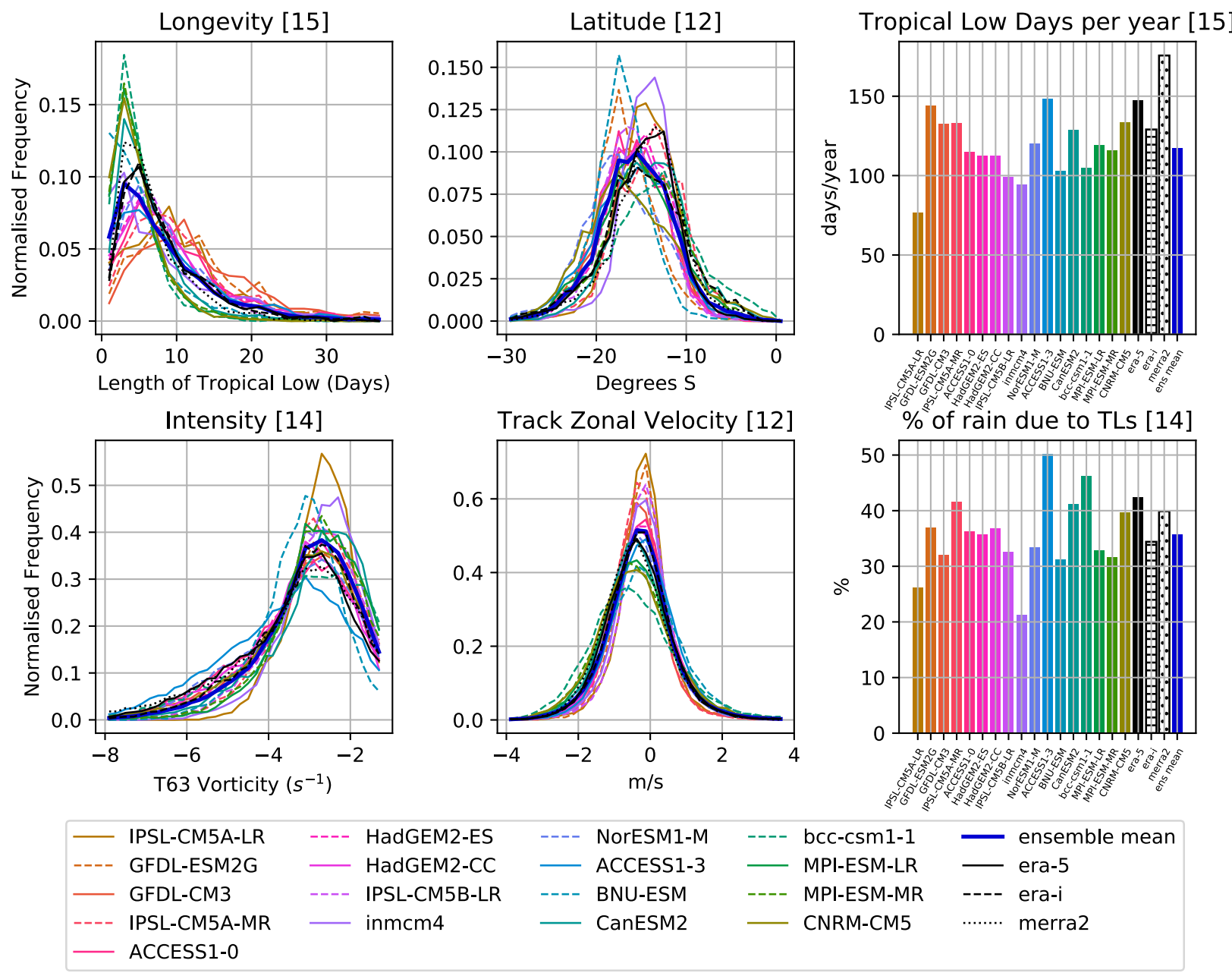

FIG. 10. (left),(center) Normalized distributions and (right) overall quantities of tropical-low properties. (top left) Longevity of TL events in days. (top center) Track latitude. (top right) Total number of tropical-low days per year for each model and reanalysis product. (bottom left) T63 filtered vorticity. (bottom center) Track zonal velocity, calculated as the tendency of the track longitude. (bottom right) Proportion of rainfall attributable to tropical lows, based on the methodology described in section $4 \mathrm{~b}$ averaged over $10^{\circ}-25^{\circ} \mathrm{S}, 15^{\circ}-30^{\circ} \mathrm{E}$. Thin colored lines indicate models, and are ordered by the maximum bin frequency in the top-left panel. Black lines show reanalysis products; thick blue lines show the ensemble mean. Numbers in square brackets indicate the number of models that show a significant change relative to natural variability at the $p<0.05$ level based on a Mann-Whitney $U$ test in the left column and based on a Welch's $t$ test in the center and right columns.

number of tropical lows per day is notably low in IPSLCM5A-LR and INM-CM4. BNU-ESM and HadGEM2ES show an overly strong peak at $20^{\circ} \mathrm{E}$, with very few tropical lows occurring outside the location of the Angola peak. For BNU-ESM, this is also clear from Fig. 3, where the track longitudes are largely confined to $18^{\circ}-23^{\circ} \mathrm{E}$. The biases of the spatial distribution of tropical lows in these climate models relative to ERA5, and their significance relative to natural variability over the 30 -yr time period, are shown in Fig. S3.

Figure 10 shows the normalized distributions of four key properties of tropical lows: their longevities, latitudes, zonal velocities, and T63 filtered vorticity. The southward shift of the tropical lows in CMIP5 models as compared to reanalysis is clearer from the latitude distribution subplot. Based on the distributions of longevity and zonal velocity, models may be divided into two groups: those with relatively more short-lived ( $<8$ days) and relatively fewer long-lived tropical lows (10-20 days) than the reanalysis products, and those with fewer shortlived and more long-lived tropical lows. Those models in the first category tend to have a wider distribution of zonal velocities, with faster track speeds, while those in the second category have a greater proportion of stationary lows concentrated around $0 \mathrm{~m} \mathrm{~s}^{-1}$. The first category therefore contains a greater proportion of transient events that move off into the Atlantic Ocean, and the second contains a greater proportion of stationary 
Angola tropical lows. Typical extreme cases for each category are CNRM-CM5 and GFDL-ESM2G. Examining Fig. 3 reveals a consistent story: for the case study year CNRM-CM5 is dominated by transient events (diagonal lines) while GFDL-ESM2G contains four to five long-lived events that meander across the continent and are frequency stationary, as well as some smaller events that are both stationary and transient. The distributions of the filtered vorticity largely follow that of reanalysis. Biases in all these quantities are significant relative to natural variability in at least 12 out of the 17 models considered.

The top-right panel of Fig. 10 shows the number of tropical-low days per year. This metric reflects the overall magnitude of the signal in Fig. 3 discussed earlier. The models with the lowest values (IPSL-CM5ALR and INM-CM4) also show a higher proportion of tropical lows just below the vorticity cutoff in the bottom-left panel of Fig. 10.

Rainfall is attributed to tropical lows under the assumption that all rainfall that falls within $5^{\circ}$ of the centroid of a tropical low is associated with that tropical low. Rainfall is decomposed into a tropical-low portion and a remainder portion. Howard et al. (2019) found that $70 \%$ of rainfall in southwest Angola and $31 \%$ of rainfall across the tropical edge region $\left(16^{\circ}-22^{\circ} \mathrm{S}\right)$ was attributable to tropical lows. The spatial pattern of rainfall attribution for CMIP5 models is shown in Fig. 11, and the overall proportion of rainfall attributed to tropical lows in each model in the region $10^{\circ}-25^{\circ} \mathrm{S}$, $15^{\circ}-30^{\circ} \mathrm{E}$ is shown in the bottom-right panel of Fig. 10 . We find that approximately $30 \%-60 \%$ of rainfall over southern Africa is associated with tropical lows between these latitudes. The spatial patterns of rainfall attribution match well with those found by Howard et al. (2019) (reproduced here in lower panels of Fig. 11). The biases of these spatial patterns relative to ERA5, and their significance relative to natural variability over the $30-\mathrm{yr}$ time period, are shown in Fig. S4.

There are some differences between tropical lows in reanalysis products and in CMIP5 models, including latitude and longevity distributions, and there is a wide distribution across models in the mean number of strong tropical-low days per year. However, tropical lows are consistently present in each model with key statistics varying by less than $20 \%$. We therefore conclude that they are sufficiently resolved to examine projected tropical-low changes and how those changes impact southern African precipitation projections.

\section{b. Future change and rainfall implications}

The overall trend in the spatial distribution of tropical lows between end-of-twenty-first-century RCP8.5 and end-of-twentieth-century historical simulations is a decrease in tropical-low frequency and in some cases a northward shift, as is shown in Fig. 12. Some models, including ACCESS1.0, HadGEM2-CC, HadGEM2-ES, and GFDL CM3, show a sharp decline in tropical lows exceeding 1 tropical-low day per $2^{\circ} \times 2^{\circ}$ box per year that is restricted to the location of the peak of their historical tropical-low locations. Northward shifts are evident in CanESM2, IPSL-CM5A-LR, and MPI-ESMLR. Only MPI-ESM-MR shows an increase in tropicallow frequency. Despite many models showing similar overall patterns in tropical-low decline, the spatial pattern of change and the location of statistically significant changes varies widely across the models. The ensemble mean exhibits an overall $15 \%$ decline in the number of tropical-low days that occur in each year.

Correspondingly, the spatial pattern of rainfall change between December and February, the main tropical-low months, shows a high degree of variation between models, consistent with Lazenby et al. (2018). Filled green and purple contours show wetting and drying of the overall seasonal mean rainfall in each model in Fig. 13. These are overlain by contours, in black and red, of the wetting and drying of the component of the rainfall attributed to tropical lows. Changes that were not significant compared to natural variability at a $p<0.05$ level were masked. It is evident that all the land-based local maxima and minima of total rainfall change located between $10^{\circ}$ and $25^{\circ} \mathrm{S}$ correspond to an associated maxima or minima in tropical-low rainfall change. Comparing with Fig. 12, these changes correspond with spatial changes in the frequency of tropical lows.

The ensemble-mean tropical-low rainfall change in this region (Fig. 13, bottom-right panel) also corresponds to the ensemble-mean tropical-low spatial distribution change (Fig. 12, bottom-right panel), with a decrease along $18^{\circ} \mathrm{S}$ centered on southeast Angola and an increase farther north. The spatial pattern of total rainfall decline maps accurately onto the spatial pattern of tropical-low rainfall decline in southern Angola and northern Namibia. However, the rainfall increase to the north of this region has its maximum farther north in the Congo and is likely delivered by other synoptic systems.

To quantify the relationship between changes in rainfall and tropical-low frequency, the Pearson's $r$ coefficient of the spatial correlation between projected rainfall change and tropical-low frequency change between $5^{\circ}-25^{\circ} \mathrm{S}$ for all land points is shown in the top row of Fig. 14. The correlation for overall rainfall is low (typically $0.1-0.3$ ) but consistently positive in all but two models. The correlation for the tropical-low rainfall component is higher, with values averaging around 0.4 . There is no consistent signal in the direction of correlation between the remaining 
Proportion of CMIP5 DJF rainfall attributed to Tropical Lows
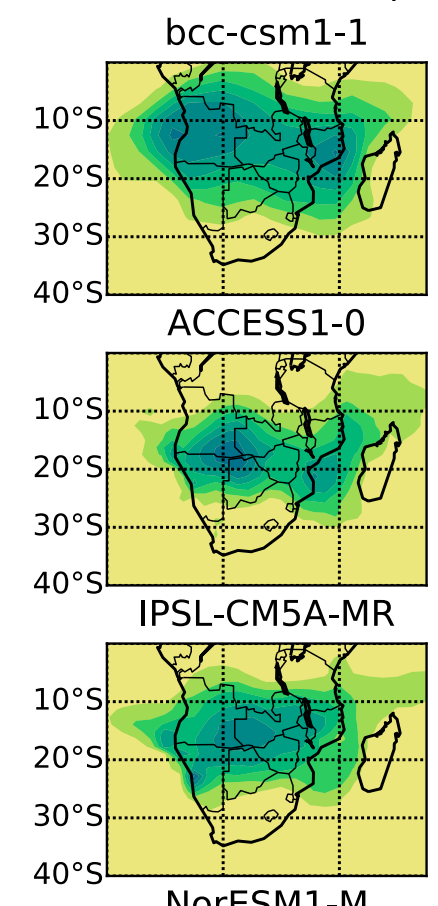

NorESM1-M

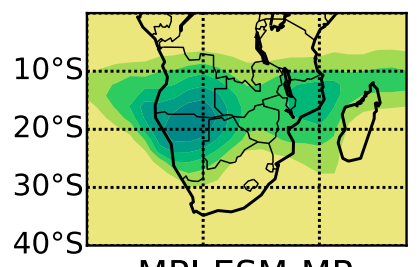

MPI-ESM-MR
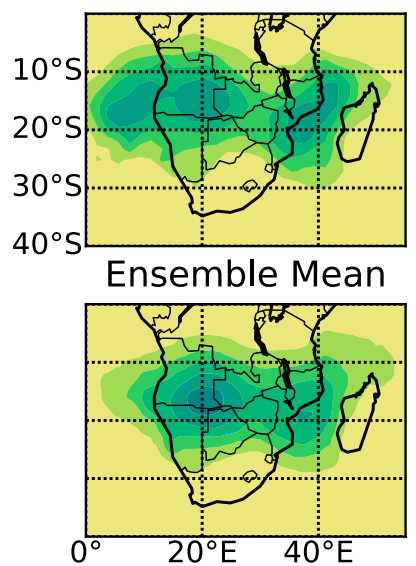

BNU-ESM

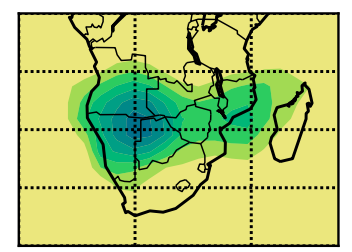

ACCESS1-3

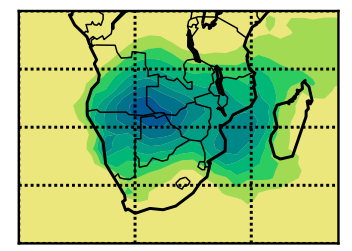

IPSL-CM5B-LR

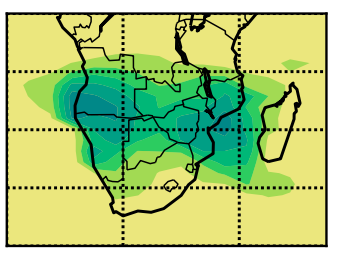

GFDL-CM3

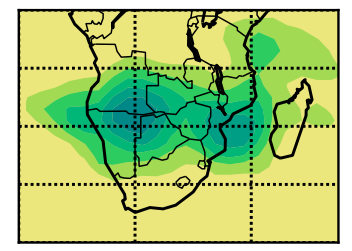

era-i

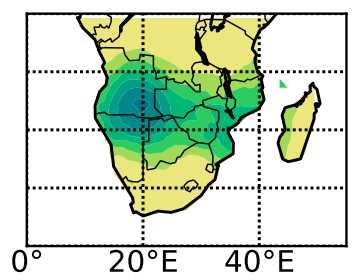

CanESM2

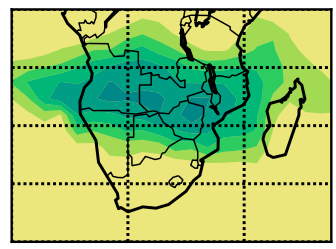

inmcm4

CNRM-CM5

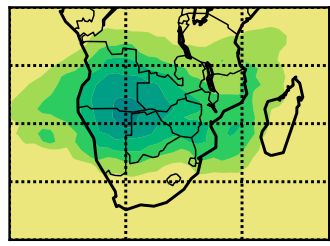

IPSL-CM5A-LR

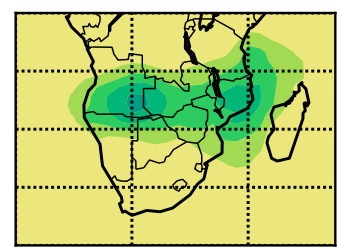

HadGEM2-CC

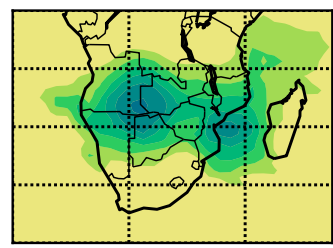

GFDL-ESM2G

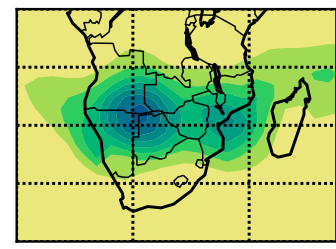

era-5

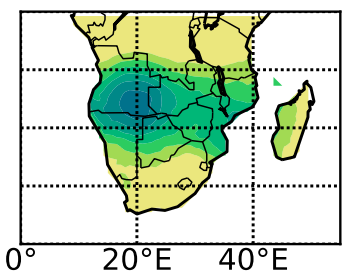

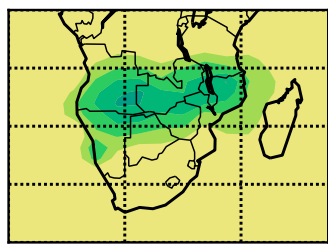

HadGEM2-ES

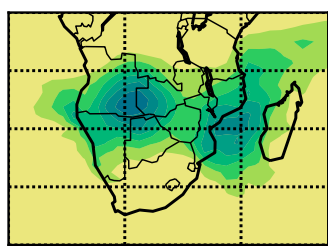

MPI-ESM-LR

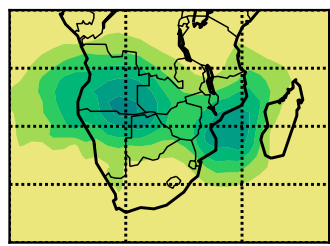

merra2

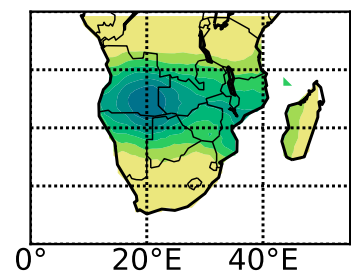

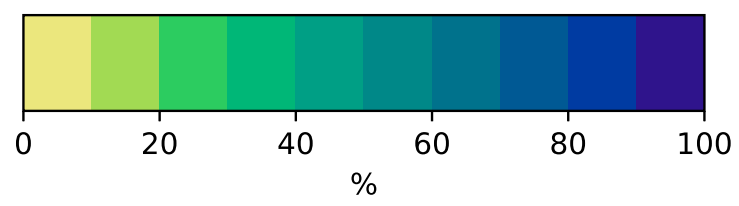

FIG. 11. Proportion of rainfall attributed to tropical lows from December to February in the historical CMIP5 sample. Rainfall is defined to be associated to a tropical low if it falls within $5^{\circ}$ of the tropical-low centroid. Panels show different CMIP5 models and the ensemble mean.

rainfall pattern change and the tropical-low distribution change. In this manner, the divergence in model rainfall projections in DJF over tropical southern Africa is linked to the uncertainty in the spatial response of tropical lows to climate change.
Averaging over land points in the region $5^{\circ}-25^{\circ} \mathrm{S}$, the projected frequency change in tropical lows is a good predictor of the intermodel spread of rainfall change $(r=0.58, p=0.015)$. This is indicated in the regression shown in Fig. 14 (bottom-left panel). The 
RCP8.5 Change in the number of tropical lows per year located in each $2 \times 2$ degree box

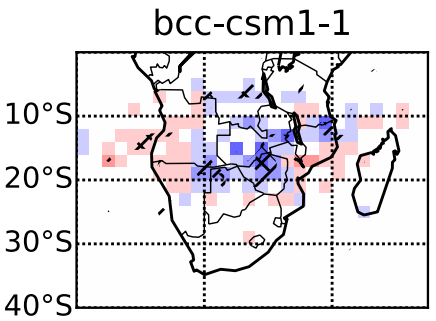

ACCESS1-0

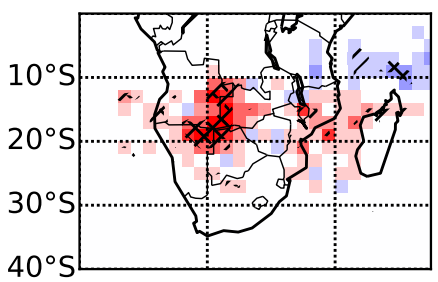

IPSL-CM5A-MR

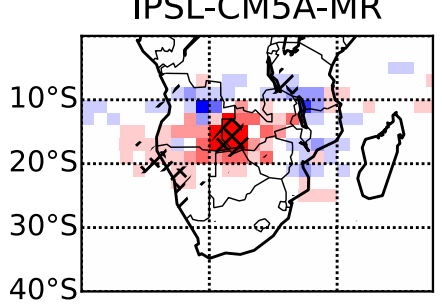

NorESM1-M

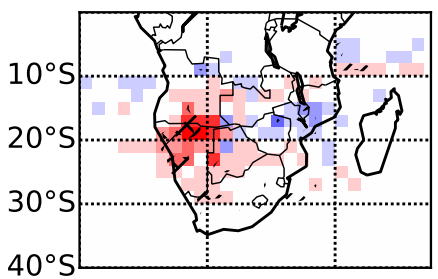

MPI-ESM-MR

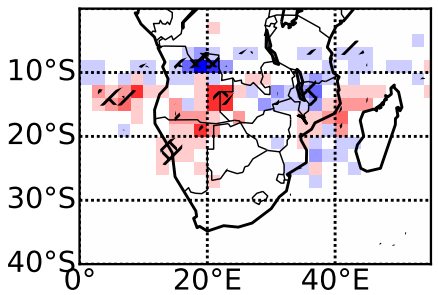

BNU-ESM

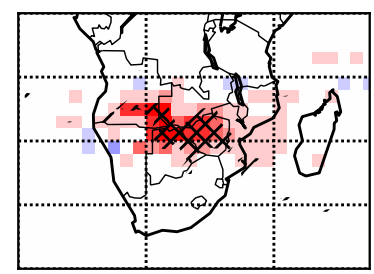

ACCESS1-3

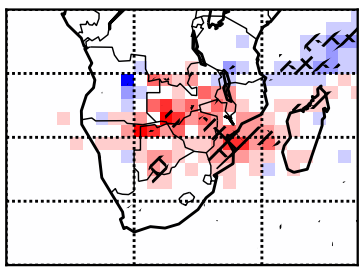

IPSL-CM5B-LR

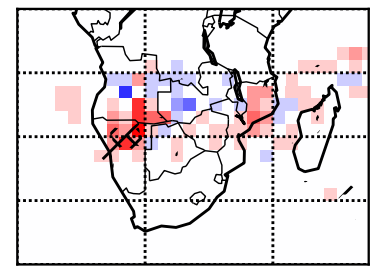

GFDL-CM3
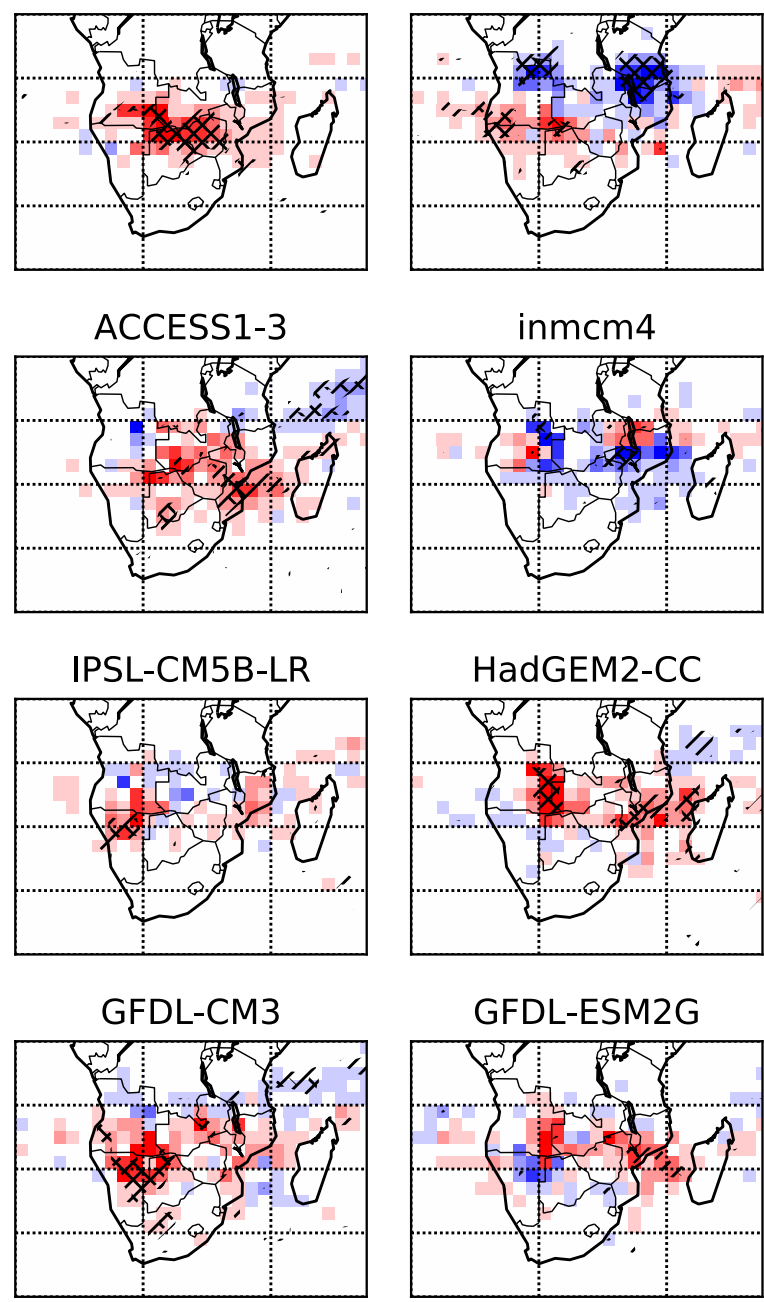

inmcm4

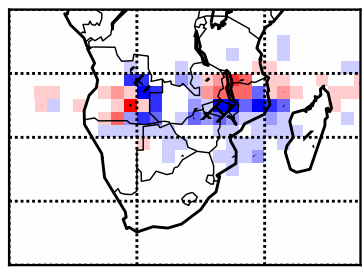

HadGEM2-CC

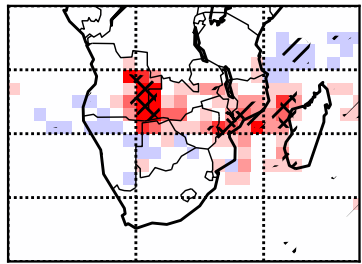

CNRM-CM5

HadGEM2-ES

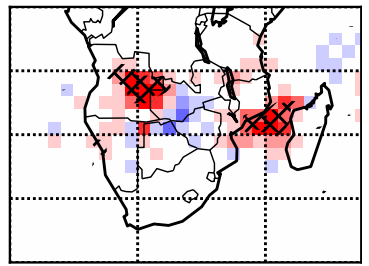

MPI-ESM-LR

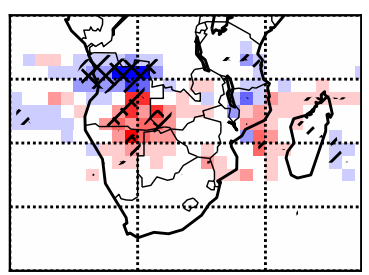

Ensemble Mean
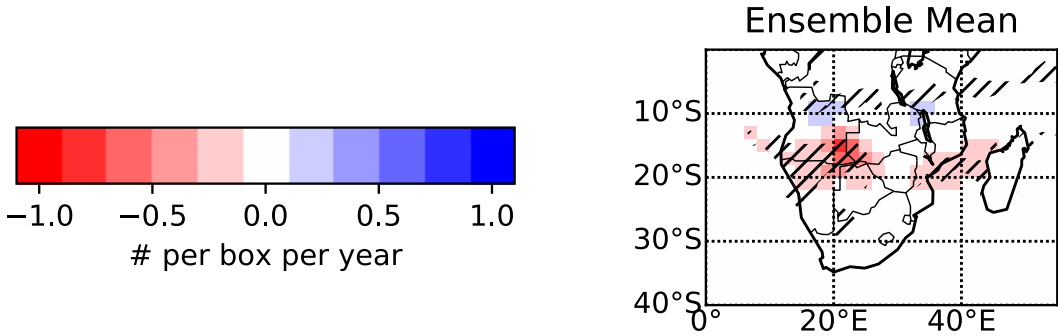

FIG. 12. Changes in the distributions of tropical lows per grid box per year between the RCP8.5 sample and the historical sample in each model and in the ensemble mean. Hatching in individual model panels indicates changes that are significant relative to interannual variability using a Welch's $t$ test. Forward (backward) hatching indicates significance at the $p<0.1(p<0.05)$ level. For the ensemble mean, forward hatching indicates changes that are significant relative to the intermodel spread at the $p<0.05$ level using a paired $t$ test.

decomposition into rainfall associated with tropical lows and a remainder component (bottom-center and bottom-right panels of Fig. 14) indicates that this influence of tropical lows is direct, as the change in tropical-low rainfall is significantly correlated with the change in tropical lows, and the change in the remainder term is not. Therefore, the spread in future projections of tropical lows is a major contributor to the spread of rainfall predictions in DJF over southern Africa. 
CMIP5 DJF rainfall change: total (colours) and tropical low component (lines)

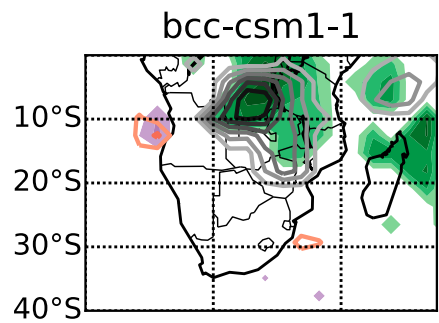

ACCESS1-0

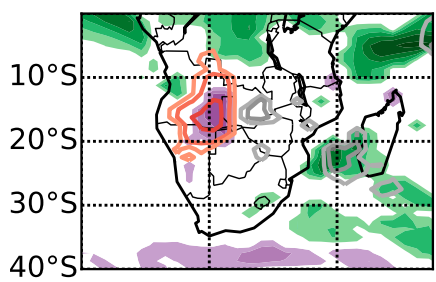

IPSL-CM5A-MR

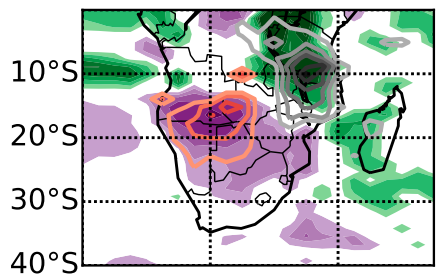

NorESM1-M

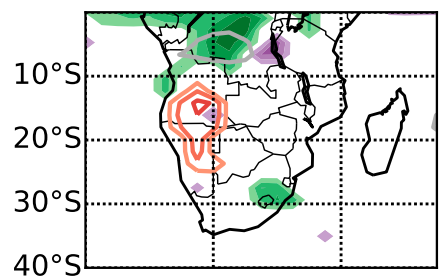

MPI-ESM-MR

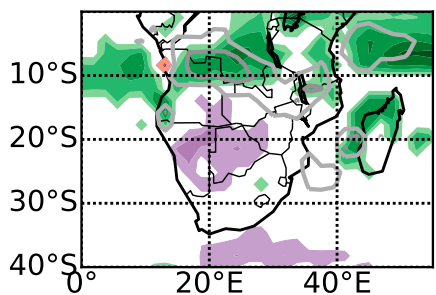

BNU-ESM

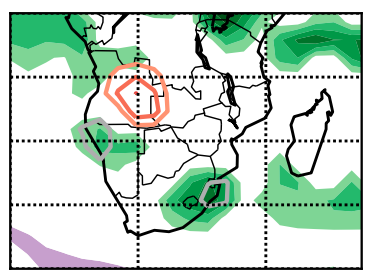

ACCESS1-3

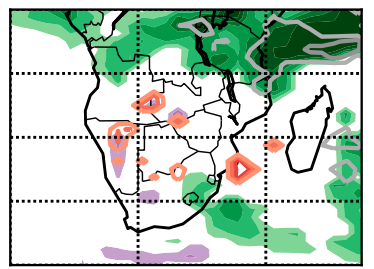

IPSL-CM5B-LR

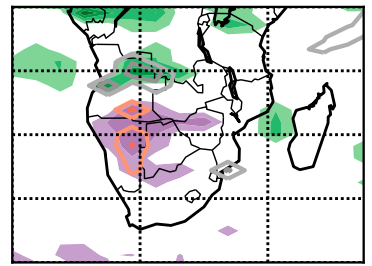

GFDL-CM3
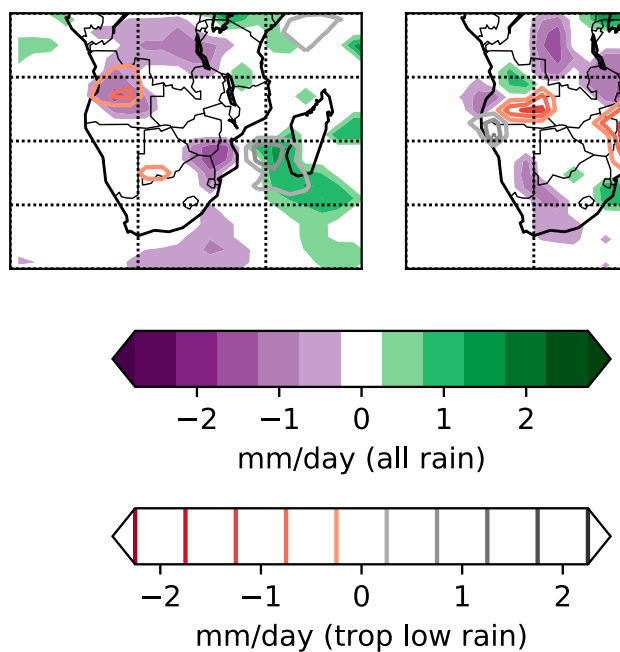

CanESM2

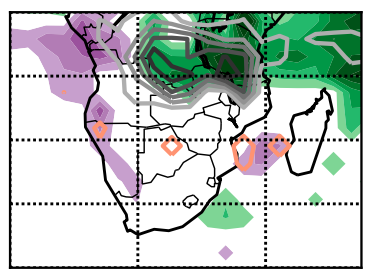

inmcm4

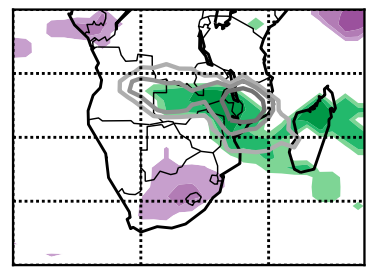

HadGEM2-CC

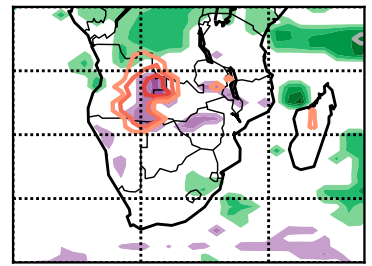

GFDL-ESM2G
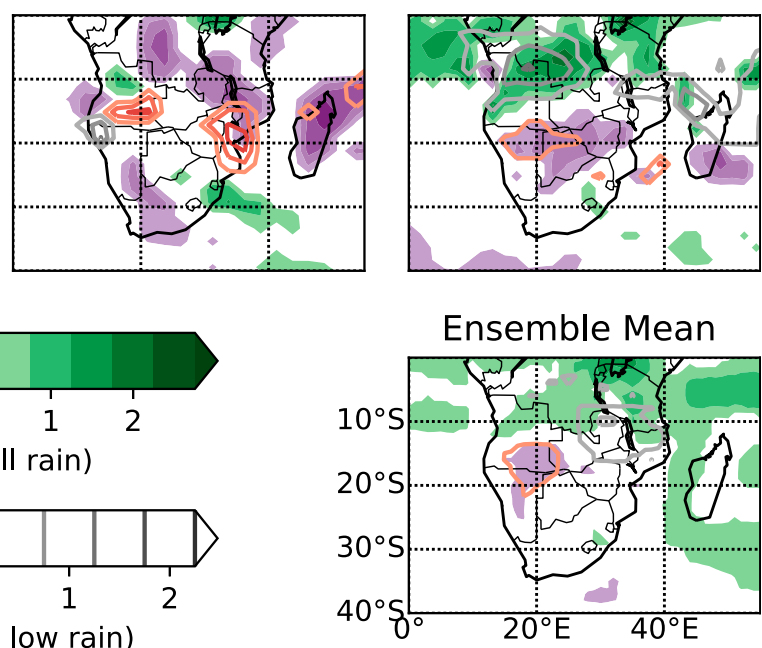

FIG. 13. Filled contours shows the total rainfall change between RCP8.5 end-of-twenty-first-century sample and historical end-of-twentiethcentury sample for December-February over southern Africa. Purple indicates a decrease and green indicates an increase. Line contours are the same as filled contours, but only for rainfall that has been attributed to tropical lows. Data that are insignificant at the $p<0.05$ level relative to interannual variability (intermodel spread) based on a Welch's $t$ test (paired $t$ test) are masked for each model (for the ensemble mean).

\section{Discussion}

\section{a. Remarks on the Congo Air Boundary}

We have found that the $\mathrm{CAB}$ is well represented in CMIP5 models, and that its projected frequency increase is able to distinguish between models that show strong and weak declines in OND rainfall south of $10^{\circ} \mathrm{S}$. In this section, we discuss the implications of the historical representation of the $\mathrm{CAB}$, and compare our results to other studies of the OND rainfall decline. 
Spatial Correlation between TL change and Rainfall Change
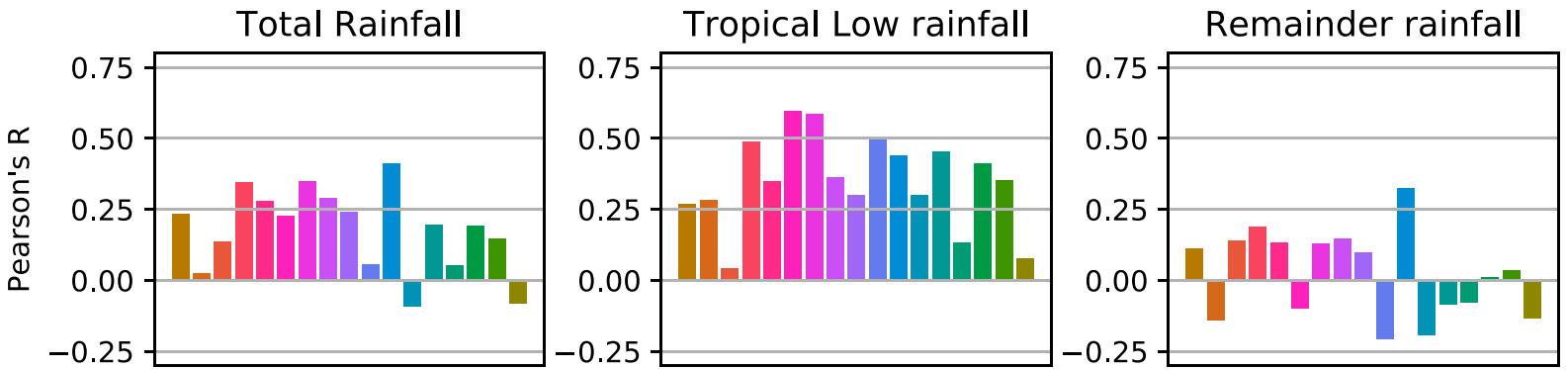

Area Averaged Regression between TL change and Rainfall Change
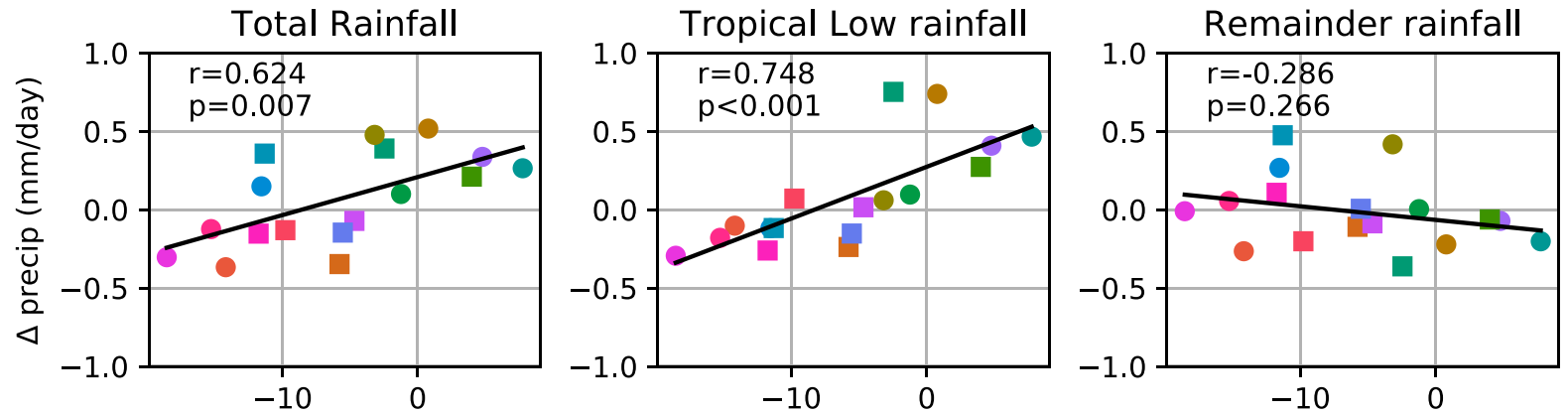

Change in number of TL days per season

\begin{tabular}{|c|c|c|c|c|c|c|c|c|}
\hline IPSL-CM5A-LR & $\bullet$ & ACCESS1-0 & - & inmcm4 & $\mathbf{\square}$ & BNU-ESM & - & MPI-ESM-LR \\
\hline GFDL-ESM2G & $\mathbf{\square}$ & HadGEM2-ES & $\mathbf{\square}$ & NorESM1-M & 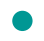 & CanESM2 & $\square$ & MPI-ESM-MR \\
\hline GFDL-CM3 & ○ & HadGEM2-CC & $\bullet$ & ACCESS1-3 & $\mathbf{\square}$ & bcc-csm1-1 & $\bullet$ & CNRM-CM5 \\
\hline IPSL-CM5A-MR & $\square$ & IPSL-CM5B-LR & & & & & & \\
\hline
\end{tabular}

FIG. 14. (top) Spatial correlation between rainfall change components and tropical-low spatial distribution change. Rainfall change and tropical-low distribution change were calculated on a $2^{\circ} \times 2^{\circ}$ grid before correlation, and only mainland points within $5^{\circ}-25^{\circ} \mathrm{S}$ were considered. (bottom) Intermodel regression between overall rainfall change and tropical-low frequency change, averaged over the same region. (left) Change in total rainfall field (center) change in rainfall located within $5^{\circ}$ of a tropical low, and (right) remainder rainfall.

The accuracy of historical representation of the $\mathrm{CAB}$ in CMIP5 models is reasonable, despite the perpendicular width of the CAB being of order $100 \mathrm{~km}$ (Howard and Washington 2019), below the resolution of most CMIP5 models. The southward displacement of the $\mathrm{CAB}$ between August and December is roughly $8^{\circ}$ of latitude, which in the coarsest models is equivalent to four grid cells, and yet the rate of the CAB's progression is very similar across models. This suggests that representation of the $\mathrm{CAB}$, and its seasonal progression, is controlled by a process that climate models do not struggle to simulate, and so is not controlled by processes that act at the grid box scale. As with the tropical rainbelt globally, the seasonal progression is clearly associated with the progression of the latitude of maximum solar insolation. Meanwhile, the sharp gradients in humidity bring to mind bifurcations into dry and moist convective states observed in idealized radiative convective equilibrium models (e.g., Emanuel et al. 2014).
We have found that projections of $\mathrm{CAB}$ frequency have different consequences north and south of the climatological CAB. The relationship between the $\mathrm{CAB}$ frequency and rainfall south of the CAB's climatological position is an intuitive one. In this region, saturation is rarely achieved when the $\mathrm{CAB}$ is present, unless extratropical processes dominate. Most rainfall comes from CAB-breakdown events. When the gradual seasonal $\mathrm{CAB}$ breakdown is delayed, as in the future model projections, there are fewer rainy days in this region, and hence less rain. Meanwhile, there is an overall increase in rainfall to the north of the climatological CAB. However, this increase is not limited to the location of the $\mathrm{CAB}$, as OND rainfall is projected to increase across much of equatorial Africa (Creese et al. 2019). Therefore, there is a consistent projected increase in rainfall in locations that are generally located the north of the $\mathrm{CAB}$, but this is not necessarily driven by the corresponding projected increase in $\mathrm{CAB}$ frequency. 
The contrasting impacts that the $\mathrm{CAB}$ frequency has to its north and south are important for determining the precise location of projected rainfall decline. Rainfall to the south of the mean $\mathrm{CAB}$ position is projected to decline due to the projected increase in CAB frequency, while rainfall to the north is projected to increase. Therefore, the CAB may be expected to set the location of the boundary of rainfall decline.

The work presented here is consistent with previous studies of rainfall projections over southern Africa. Dunning et al. (2018) found that the seasonal progression of the African rain belt is tied up in the strengths of the Saharan and Angola heat lows, both of which are projected to intensify in a warmer world. Munday and Washington (2019) found a similar result, that models with a deeper future Angola heat low showed a higher intensity of drying, while Cook and Vizy (2013) observed a strengthening of the heat low in regional climate model simulations. The Angola heat low is intrinsically linked to the CAB (Howard and Washington 2019), being consistently located approximately $1^{\circ}$ south of the $\mathrm{CAB}$ and sharing circulation features. Therefore, an increase in the climatological $\mathrm{CAB}$ frequency corresponds to an increase in the heatlow intensity.

By applying the Chadwick et al. (2013) decomposition, Lazenby et al. (2018) attributed the OND rainfall change to dynamic rather than thermodynamic changes, associated with spatial shifts in the pattern of convective mass fluxes. In the context of this methodology, it is useful to consider the atmosphere to the north of the $\mathrm{CAB}$ and during $\mathrm{CAB}$ breakdown events as capable of deep convection, and to the south of the $\mathrm{CAB}$ as incapable of deep convection. The increased $\mathrm{CAB}$ frequency corresponds to a decrease in the proportion of the time that convection may occur in the region south of $10^{\circ} \mathrm{S}$, and so is associated with a shift in deep convection away from southern Africa.

Figures $3 \mathrm{f}$ and $3 \mathrm{~g}$ in Lazenby et al. (2018) also demonstrated that there was a decrease in near surface relative humidity between $10^{\circ}$ and $20^{\circ} \mathrm{S}$, but that this did not contribute to the overall precipitation change budget. This finding underscores the fundamental concept outlined by the CAB: that the southern African atmosphere during the austral spring is often characterized at any instant by a dichotomy of states: one that is severely moisture limited and one that is close to saturated, with very little in between (Howard and Washington 2019). In such a scenario, small thermodynamic perturbations have less potential to change the likelihood of convection than small dynamical perturbations. This is because a dynamical perturbation may move the moist airmass into, or away from a given location, drastically changing the likelihood of convection at that spot. Meanwhile, a small change in saturation temperature is unlikely to change the likelihood of convection if the atmosphere is either severely dry or not at all moisture limited.

\section{b. Remarks on tropical lows}

Uncertainty in future projections of tropical lows in southern Africa has been identified as a source of the uncertainty and broad model spread in rainfall projections in this region during the main rainy season. This uncertainty derives from variations in the changes of the climatological tropical-low spatial distribution; however, some robust changes are present, as discussed below.

The historical spatial distribution of tropical-lows features a southward bias as compared to reanalysis. Models show a greater proportion of tropical lows centered near $18^{\circ} \mathrm{S}$ and too few located around $15^{\circ} \mathrm{S}$. This bias is consistent with other studies of the historical CMIP5 rainfall bias over southern Africa. An interannual southward shift in the Angola low has been associated with an increase in rainfall over subtropical southern Africa (Pascale et al. 2019; Crétat et al. 2018), consistent with the direction of the rainfall bias (Lazenby et al. 2016). Furthermore, Munday and Washington (2017) found a correlation between the magnitude of this wet bias and the strength of the Angola low, which they found was overly intense in most models. They also found that the climatological position of the Angola low was shifted toward the Angola-Namibia border in many models.

Despite differences in the patterns, there is a consensus in all but one model of overall tropical-low decline south of $15^{\circ} \mathrm{S}$. This is reflected in the ensemble mean of both precipitation and tropical-low location shifts. A large minority of models also show a marked increase in tropical lows north of this line, signifying a northward shift. However, this change is less robust than the decline farther south. A northward shift and overall decline of tropical-low location mirror the characteristic response of tropical lows to El Niño events (Howard et al. 2019; Pascale et al. 2019).

Lazenby et al. (2018) proposed that the diverse range of future projections in DJF is associated with intermodel differences in the SST changes in the Indian and Atlantic Oceans. Since interannual variability of the Angola low, which in late summer is the climatological expression of tropical lows, is sensitive to SSTs in these oceans (Pascale et al. 2019), it is likely that variability in SST projections may lead to variability in tropical-low distributions, which in turn lead to the spread of projected rainfall changes. 


\section{Conclusions}

The CMIP5 ensemble predicts a drying trend in both spring and summer in southern Africa. Spring drying is robust across all models, and is associated with a delay in the wet-season onset (Dunning et al. 2018). Such delays would cause a shortening of the growing season, impacting regional agriculture and food security (Lobell et al. 2008; Schlenker and Lobell 2010). Model projections in the summer are more divergent and the ensemble-mean drying trend in this season is less robust. However, rainfall changes in this season would be equally disruptive to the local economy. For this reason, it is imperative that the mechanisms of future rainfall change demonstrated by CMIP5 models are well understood.

The present study has placed the spring and summer projected rainfall change in the context of two classes of weather events: tropical lows and the CAB. These features are predominant in each respective season and are sufficiently well resolved in the climate models. By doing so, we have attributed model consensus on spring drying to increases in $\mathrm{CAB}$ frequency and latitude, and the lack of model consensus on summer rainfall change to uncertainty in the tropical-low response to a warmer world. This work provides crucial context for the projected changes and grounds changes to the local climate in meteorological theory.

We have found that the spring drying trend is strongly correlated across models with an increased frequency in the $\mathrm{CAB}$. This delayed breakdown causes an increase in its average frequency between October and December of approximately $13 \%$. Model consensus on its projected change agree that the $\mathrm{CAB}$ will be located $0.5^{\circ}-1^{\circ}$ farther north and its gradual seasonal decline will occur half a month later at the end of twenty-first century than the twentieth under the RCP8.5 scenario. These changes are significant as against internal variability in $12-15$ of the 18 models. Therefore, we strongly advocate for further research into this understudied feature of the climate system, particularly in the form of observational field campaigns.

Tropical lows, which make up the synoptic expression of the Angola low in the southern African summer, show more model spread in their future change, particularly when considering small-scale spatial shifts. This increased model uncertainty is a contributor to the divergence of DJF rainfall projections in southern Africa. However, despite spatial differences, a statistically significant decline in tropical-low frequency south of $15^{\circ} \mathrm{S}$ is present in 11 models, with an overall ensemble-mean decline of $10 \%$. The response of tropical lows to future warming will be important for rainfall change in this region.

Acknowledgments. This work has been generously supported by the Origin Foundation John Monash
Scholarship and by the Future Climate for Africa UMFULA project, with financial support from the U.K. Natural Environment Research Council (NERC), NE/M020207/1, and the U.K. Government's Department for International Development (DfID). The GCM data used in this study were made available through the Earth System Grid Federation (ESGF) Peer-to-Peer system (http://data.ceda.ac.uk/badc/cmip5/). Reanalysis data used in this analysis were provided by the Copernicus Climate Change Service (https://cds.climate.copernicus.eu/ cdsapp\#!/home; Hersbach et al. 2020), the European Centre for Medium-Range Weather Forecasts (https://apps. ecmwf.int/datasets/data/interim-full-daily/levtype $=\mathrm{pl} /$ ), and NASA (https://disc.sci.gsfc.nasa.gov/daac-bin/FTPSubset.pl). Color maps were sourced from cmocean (https://matplotlib. org/cmocean/). We thank Kevin Hodges for access to TRACK, three anonymous reviewers for their helpful comments, and Paul-Arthur Monerie for assistance regarding decadal variability.

\section{REFERENCES}

Aloysius, N. R., J. Sheffield, J. E. Saiers, H. Li, and E. F. Wood, 2016: Evaluation of historical and future simulations of precipitation and temperature in central Africa from CMIP5 climate models. J. Geophys. Res. Atmos., 121, 130-152, https:// doi.org/10.1002/2015JD023656.

Baray, J., S. Baldy, R. Diab, and J. Cammas, 2003: Dynamical study of a tropical cut-off low over South Africa, and its impact on tropospheric ozone. Atmos. Environ., 37, 1475-1488, https:// doi.org/10.1016/S1352-2310(02)00999-8.

Bengtsson, L., K. I. Hodges, M. Esch, N. Keenlyside, L. Kornblueh, J. J. Luo, and T. Yamagata, 2007: How may tropical cyclones change in a warmer climate? Tellus, 59A, 539-561, https://doi.org/10.1111/j.1600-0870.2007. 00251.x

Canny, J., 1986: A computational approach to edge detection. IEEE Trans. Pattern Anal. Mach. Int., 8, 679-698, https:// doi.org/10.1109/TPAMI.1986.4767851.

Chadwick, R. S., I. Boutle, and G. Martin, 2013: Spatial patterns of precipitation change in CMIP5: Why the rich do not get richer in the tropics. J. Climate, 26, 3803-3822, https://doi.org/ 10.1175/JCLI-D-12-00543.1.

Chou, C., J. D. Neelin, C. A. Chen, and J. Y. Tu, 2009: Evaluating the "rich-get-richer" mechanism in tropical precipitation change under global warming. J. Climate, 22, 1982-2005, https://doi.org/10.1175/2008JCLI2471.1.

Conway, D., and Coauthors, 2015: Climate and southern Africa's water-energy-food nexus. Nat. Climate Change, 5, 837-846, https://doi.org/10.1038/nclimate2735.

Cook, C., C. J. Reason, and B. C. Hewitson, 2004: Wet and dry spells within particularly wet and dry summers in the South African summer rainfall region. Climate Res., 26, 17-31, https://doi.org/10.3354/cr026017.

Cook, K. H., and E. K. Vizy, 2013: Projected changes in East African rainy seasons. J. Climate, 26, 5931-5948, https://oi.org/10.1175/ JCLI-D-12-00455.1.

Creese, A., R. Washington, and C. Munday, 2019: The plausibility of September-November Congo basin rainfall change in 
coupled climate models. J. Geophys. Res. Atmos., 124, 58225846, https://doi.org/10.1029/2018JD029847.

Crétat, J., B. Pohl, B. Dieppois, S. Berthou, and J. Pergaud, 2018: The Angola low: Relationship with southern African rainfall and ENSO. Climate Dyn., 52, 1783-1803, https://doi.org/ 10.1007/s00382-018-4222-3.

Dare, R. A., N. E. Davidson, and J. L. McBride, 2012: Tropical cyclone contribution to rainfall over Australia. Mon. Wea. Rev., 140, 3606-3619, https://doi.org/10.1175/MWR-D-11-00340.1.

Dunning, C. M., E. C. Black, and R. P. Allan, 2018: Later wet seasons with more intense rainfall over Africa under future climate change. J. Climate, 31, 9719-9738, https://doi.org/10.1175/JCLI-D-18-0102.1.

Emanuel, K., A. A. Wing, and E. M. Vincent, 2014: Radiativeconvective instability. J. Adv. Model. Earth Syst., 6, 75-90, https://doi.org/10.1002/2013MS000270.

Hachigonta, S., C. J. Reason, and M. Tadross, 2008: An analysis of onset date and rainy season duration over Zambia. Theor. Appl. Climatol., 91, 229-243, https://doi.org/10.1007/s00704-007-0306-4.

Held, I. M., and B. J. Soden, 2006: Robust responses of the hydrological cycle to global warming. J. Climate, 19, 5686-5699, https://doi.org/10.1175/JCLI3990.1.

Hersbach, H., and Coauthors, 2020: The ERA5 global reanalysis. Quart. J. Roy. Meteor. Soc., https://doi.org/10.1002/qj.3803, in press.

Hodges, K. I., 1994: A general method for tracking analysis and its application to meteorological data. Mon. Wea. Rev., 122, 2573-2586, https://doi.org/10.1175/1520-0493(1994)122<2573: AGMFTA $>2.0 . \mathrm{CO} ; 2$.

- 1999: Adaptive constraints for feature tracking. Mon. Wea. Rev., 127, 1362-1373, https://doi.org/10.1175/1520-0493(1999) $127<1362$ :ACFFT $>2.0 . \mathrm{CO} ; 2$.

— A. Cobb, and P. L. Vidale, 2017: How well are tropical cyclones represented in reanalysis datasets? J. Climate, 30, 52435264, https://doi.org/10.1175/JCLI-D-16-0557.1.

Howard, E., and R. Washington, 2018: Characterizing the synoptic expression of the Angola low. J. Climate, 31, 7147-7165, https://doi.org/10.1175/JCLI-D-18-0017.1.

— and - 2019: Drylines in southern Africa: Rediscovering the Congo air boundary. J. Climate, 32, 8223-8242, https:// doi.org/10.1175/JCLI-D-19-0437.1.

, — _ , and K. I. Hodges, 2019: Tropical lows in southern Africa: Tracks, rainfall contributions, and the role of ENSO. J. Geophys. Res. Atmos., 124, 11 009-11 032, https://doi.org/ 10.1029/2019JD030803.

James, R., and R. Washington, 2013: Changes in African temperature and precipitation associated with degrees of global warming. Climatic Change, 117, 859-872, https://doi.org/10.1007/s10584-012-0581-7.

Jiang, Y., L. Zhou, C. J. Tucker, A. Raghavendra, W. Hua, Y. Y. Liu, and J. Joiner, 2019: Widespread increase of boreal summer dry season length over the Congo rainforest. Nat. Climate Change, 9, 617-622, https://doi.org/10.1038/s41558-019-0512-y.

Khouakhi, A., G. Villarini, and G. A. Vecchi, 2017: Contribution of tropical cyclones to rainfall at the global scale. J. Climate, 30, 359-372, https://doi.org/10.1175/JCLI-D-16-0298.1.

Kniveton, D. R., R. Layberry, C. J. R. Williams, and M. Peck, 2009: Trends in the start of the wet season over Africa. Int. J. Climatol., 29, 1216-1225, https://doi.org/10.1002/joc.1792.

Lavender, S. L., and D. J. Abbs, 2013: Trends in Australian rainfall: Contribution of tropical cyclones and closed lows. Climate Dyn., 40, 317-326, https://doi.org/10.1007/s00382-012-1566-y.

Lazenby, M. J., M. C. Todd, and Y. Wang, 2016: Climate model simulation of the south Indian Ocean convergence zone: Mean state and variability. Climate Res., 68, 59-71, https://doi.org/ $10.3354 / \mathrm{cr} 01382$.
,,-- R. S. Chadwick, and Y. Wang, 2018: Future precipitation projections over central and southern Africa and the adjacent Indian Ocean: What causes the changes and the uncertainty? J. Climate, 31, 4807-4826, https://doi.org/10.1175/ JCLI-D-17-0311.1.

Leroux, M., 2001: The climate of tropical Africa. The Meteorology and Climate of Tropical Africa. Springer-Praxis, 39-45.

Lobell, D. B., M. B. Burke, C. Tebardi, M. D. Mastrandrea, W. P. Falcon, and R. L. Naylor, 2008: Prioritizing climate change adaptation needs for food security in 2030. Science, 319, 607610, https://doi.org/10.1126/science.1152339.

Munday, C., and R. Washington, 2017: Circulation controls on southern African precipitation in coupled models: The role of the Angola low. J. Geophys. Res. Atmos., 122, 861-877, https:// doi.org/10.1002/2016JD025736.

— jections of early summer drying over southern Africa. J. Climate, 32, 3707-3725, https://doi.org/10.1175/JCLI-D-18-0463.1.

Pascale, S., B. Pohl, S. B. Kapnick, and H. Zhang, 2019: On the Angola low interannual variability and its role in modulating ENSO effects in southern Africa. J. Climate, 32, 4783-4803, https://doi.org/10.1175/JCLI-D-18-0745.1.

Rastogi, D., M. Ashfaq, L. R. Leung, S. Ghosh, A. Saha, K. I. Hodges, and K. Evans, 2018: Characteristics of Bay of Bengal monsoon depressions in the 21st century. Geophys. Res. Lett., 45, 6637-6645, https://doi.org/10.1029/2018GL078756.

Reason, C. J., and D. Jagadheesha, 2005: A model investigation of recent ENSO impacts over southern Africa. Meteor. Atmos. Phys., 89, 181-205, https://doi.org/10.1007/s00703-005-0128-9.

Rowell, D. P., and R. S. Chadwick, 2018: Causes of the uncertainty in projections of tropical terrestrial rainfall change: East Africa. J. Climate, 31, 5977-5995, https://doi.org/10.1175/JCLI-D-17-0830.1.

Sardeshmukh, P. D., and B. J. Hoskins, 1988: The generation of global rotational flow by steady idealized tropical divergence. J. Atmos. Sci., 45, 1228-1251, https://doi.org/10.1175/15200469(1988)045<1228:TGOGRF>2.0.CO;2.

Scheff, J., and D. Frierson, 2012a: Twenty-first-century multimodel subtropical precipitation declines are mostly midlatitude shifts. J. Climate, 25, 4330-4347, https://doi.org/10.1175/JCLI-D-11-00393.1. , and $\longrightarrow$, 2012b: Robust future precipitation declines in CMIP5 largely reflect the poleward expansion of model subtropical dry zones. Geophys. Res. Lett., 39, L18704, https:// doi.org/10.1029/2012GL052910.

Schlenker, W., and D. B. Lobell, 2010: Robust negative impacts of climate change on African agriculture. Environ. Res. Lett., 5, 014010, https://doi.org/10.1088/1748-9326/5/1/014010.

Taljaard, J. J., 1953: The mean circulation in the lower troposphere over southern Africa. S. Afr. Geogr. J., 35, 33-45, https:// doi.org/10.1080/03736245.1953.10559299.

_ 1972: Synoptic meteorology of the Southern Hemisphere. Meteorology of the Southern Hemisphere, Meteor. Monogr., No. 35, Amer. Meteor. Soc., 139-213.

- 1986: Change of rainfall distribution and circulation patterns over southern Africa in summer. J. Climatol., 6, 579-592, https://doi.org/10.1002/joc.3370060602.

Torrance, J. D., 1979: Upper windflow patterns in relation to rainfall in south-east central Africa. Weather, 34, 106-115, https://doi.org/10.1002/j.1477-8696.1979.tb03418.x.

van Heerden, J., and J. J. Taljaard, 1998: Africa and surrounding waters. Meteorology of the Southern Hemisphere, Meteor. Monogr., No. 49, Amer. Meteor. Soc., 141-174, https://doi.org/ 10.1007/978-1-935704-10-2_6. 